\title{
Grapefruit-derived nanovectors deliver miR-18a for treatment of liver metastasis of colon cancer by induction of M1 macrophages
}

\author{
Yun Teng', Jingyao $\mathrm{Mu}^{2}$, Xin $\mathrm{Hu}^{4,5}$, Abhilash Samykutty ${ }^{2}$, Xiaoying Zhuang ${ }^{2}$, \\ Zhongbin Deng', Lifeng Zhang², Pengxiao $\mathrm{Cao}^{2}$, Jun Yan², Donald Miller ${ }^{2}$, Huang- \\ Ge Zhang ${ }^{1,2,3}$ \\ ${ }^{1}$ Robley Rex VA Medical Center, Louisville, KY 40206, USA \\ ${ }^{2}$ James Graham Brown Cancer Center, University of Louisville, Louisville, KY 40202, USA \\ ${ }^{3}$ Department of Microbiology and Immunology, University of Louisville, Louisville, KY 40202, USA \\ ${ }^{4}$ Program in Biostatistics, Bioinformatics and Systems Biology, The University of Texas Graduate School of Biomedical \\ Sciences at Houston, Houston, TX 77030, USA \\ ${ }^{5}$ Department of Genomic Medicine, The University of Texas MD Anderson Cancer Center, Houston, TX 77030, USA
}

Correspondence to: Huang-Ge Zhang, e-mail: H0Zhan17@louisville.edu

Keywords: miR-18a, M1 Kupffer cells, grapefruit-derived nanovector, IRF2, liver metastasis of colon cancer

Received: November 02, 2015

Accepted: March 10, 2016

Published: March 25, 2016

\section{ABSTRACT}

Liver metastasis accounts for many of the cancer deaths in patients. Effective treatment for metastatic liver tumors is not available. Here, we provide evidence for the role of miR-18a in the induction of liver M1 (F4/80+interferon gamma (IFNY) ${ }^{+}$IL-12 ${ }^{+}$) macrophages. We found that miR-18a encapsulated in grapefruit-derived nanovector (GNV) mediated inhibition of liver metastasis that is dependent upon the induction of $\mathrm{M1}\left(\mathrm{F} 4 / 80^{+} \mathrm{IFNy} \mathrm{YL}^{+}-12^{+}\right)$macrophages; depletion of macrophages eliminated its anti-metastasis effect. Furthermore, the miR-18a mediated induction of macrophage IFNy by targeting IRF2 is required for subsequent induction of IL-12. IL-12 then activates natural killer (NK) and natural killer T (NKT) cells for inhibition of liver metastasis of colon cancer. This conclusion is supported by the fact that knockout of IFNy eliminates miR-18a mediated induction of IL-12, miR-18a treatment has an antimetastatic effects in $\mathrm{T}$ cell deficient mice but there is no anti-metastatic effect on NK and NKT deficient mice. Co-delivery of miR-18a and siRNA IL-12 to macrophages did not result in activation of co-cultured NK and NKT cells. Taken together our results indicate that miR-18a can act as an inhibitor for liver metastasis through induction of M1 macrophages.

\section{INTRODUCTION}

Metastasis accounts for the majority of cancer deaths. The liver is a frequent site of metastasis of many different types of cancer, including colon cancer. Liver macrophages (Kupffer cells; KCs) play a crucial role in the pathogenesis of liver tumor metastasis and are a major component of the microenvironment of primary and metastatic liver tumors. Direct and indirect activation of KCs results in the production of factors and cytokines capable of facilitating both anti-tumor [1-5] and protumor effects [6-8]. More importantly, Kupffer cells are situated in the hepatic sinusoids to encounter circulating
$\mathrm{T}$ cells, as well as natural killer (NK) and natural killer T (NKT) cells, and modulate activity of these lymphocytes. Interaction with these immune cell populations is required to develop the full potential of KCs to mediate antitumor immunity [9-12]. Therefore, targeted delivery of therapeutic agents to liver KCs could enhance anti-tumor immune functions.

Evidence is provided that liver macrophages can make M1 or M2 responses. M1 and M2 macrophages promote Th1 and Th2 responses, respectively. M2 macrophages are a major component of the leukocyte infiltrate of tumors. M2 macrophages suppress NK, NKT, and T-cell activation and proliferation by releasing 
transforming growth factor beta (TGF- $\beta$ ) [13-19]. Moreover, they have an interleukin (IL)-12 $2^{\text {low }}$ phenotype, characteristic of M2 cells. By expressing properties of polarized M2 cells, M2 participate in circuits that regulate tumor growth and progression, adaptive immunity, stroma formation and angiogenesis. This raises the possibility that the molecules and cells involved might represent novel and valuable therapeutic targets. As for M1 macrophages, these macrophages produce IL-12 [16, 20-24] to promote tumoricidal responses. The mechanisms governing macrophage polarization are unclear.

MicroRNAs (miRNAs) are a class of small, noncoding RNAs that post-transcriptionally control the translation and stability of mRNAs. Hundreds of miRNAs are known to have dysregulated expression in cancer [25-30]. Studies evaluating their biological and molecular roles and their potential therapeutic applications are emerging. The levels of miRNAs expressed in myeloid cells have effects on the polarization of M1 versus M2 macrophages [31-36]. Targeted delivery of miRNAs to macrophages as an alternative strategy for treatment of cancer by induction of M1 macrophages has not been fully developed.

MiR-18a, an important member of miR-17-92 family, has been shown various effects on different tumors. It was reported that miR-18a could act as a tumor suppressor. Our previous study published showed that miR18a suppresses colon tumor growth by targeting $\beta$-catenin expressed in the colon tumor cells. The effects of miR-18a on the polarization of M1 versus M2 macrophages have not been reported. We attempted to predict the potential target genes of miR-18a through applying a bioinformatics analysis method (TargetScan). We found Irf2, a theoretical target gene of miR-18a with the specific binding site in the 3'-UTR sequence. IL-12 is dysregulated in macrophages from Irf2 knockout mice. This finding led us to choose miR-18a as an example to test whether a grapefruitderived nanovector (GNV) based delivery system can be used for targeted delivery of therapeutic miRNA to liver macrophages and treat liver metastasis.

\section{RESULTS}

\section{Optimization of efficiency of OGNVs for encapsulating RNA}

We first tested whether the efficiency of OGNVs for encapsulating RNA in general can be increased by Ultraviolet (UV) cross-linking lipids extracted from grapefruit nanoparticles with RNAs extracted from CT26 cells. Lipids extracted from sucrose gradient purified grapefruit nanoparticles (Supplementary Figure S1) and cellular RNA were mixed and exposed to different doses of UV light (254 nm) using a Spectrolinker. The results showed that lipids pre-exposed to UV radiation at 250 millijoules seconds per $\mathrm{cm}^{2}\left(\mathrm{~mJ} / \mathrm{cm}^{2}\right)$ and $500 \mathrm{~mJ} / \mathrm{cm}^{2}$ reassembled into OGNVs with a diameter of $110.7 \pm$ $22.5 \mathrm{~nm}$ (means \pm standard error of the mean (SEM)) and $120.6 \pm 15.7 \mathrm{~nm}$, respectively (Supplementary Figure S2A). Both doses of UV radiation resulted in an increased efficiency of encapsulation for RNA from $5.5 \pm 2.2 \%$ to $28.2 \pm 4.8 \%$ and $30.6 \pm 4.5 \%$, respectively (Supplementary Figure S2B). However, further increasing the dose of UV $\left(1,000 \mathrm{~mJ} / \mathrm{cm}^{2}\right.$ and $\left.2,000 \mathrm{~mJ} / \mathrm{cm}^{2}\right)$ resulted in decreasing the encapsulation efficiency of RNA.

Next, we tested whether neutralizing negative charges of the RNAs might further enhance the efficiency of encapsulation of RNA in OGNVs. OGNVs were assembled by sonication of grapefruit nanoparticle-derived lipids with RNA pre-dissolved in $\mathrm{H}_{2} \mathrm{O}$, phosphate buffered saline (PBS, $\mathrm{pH} 7.4$ ), and $155 \mathrm{mM}$ sodium chloride $(\mathrm{NaCl})$. Using $155 \mathrm{mM} \mathrm{NaCl}$ caused a 4.3-fold and 3.9-fold more efficient encapsulation of RNA than $\mathrm{H}_{2} \mathrm{O}$ and PBS, respectively (Supplementary Figure S2C). Furthermore, an additive effect was observed when $\mathrm{NaCl}$ was combined with UV radiation (Supplementary Figure S2C). The efficiency of encapsulation of RNA when placed in $\mathrm{NaCl}$ and exposed to UV radiation was increased markedly in comparison with $\mathrm{H}_{2} \mathrm{O}$ combined with UV exposure (49.6\% vs $27.32 \%)$ or PBS combined with UV exposure (49.6\% vs $28.62 \%$ ). Collectively, the combination of UV radiation $\left(500 \mathrm{~mJ} / \mathrm{cm}^{2}\right)$ and $\mathrm{NaCl}(155 \mathrm{mM})$ provides optimal conditions for enhancing RNA encapsulation efficiency in OGNVs. Henceforth we refer to the nanovectors made under these conditions as optimized-GNVs (OGNVs).

To determine whether $\mathrm{UV}$ radiation and $\mathrm{NaCl}$ have an effect on the functional characteristics of RNA encapsulated in OGNVs, we evaluated the size (Supplementary Figure S3A, S3B) and potential distribution (Supplementary Figure S3C) of OGNVs using a Zetasizer Nano ZS. With UV radiation, the average diameter of the OGNVs was 156 $\pm 33 \mathrm{~nm}$ in $\mathrm{NaCl}$, in comparison with $125 \pm 22 \mathrm{~nm}$ in $\mathrm{H}_{2} \mathrm{O}$, and $188 \pm 28 \mathrm{~nm}$ in PBS. Zeta potential analysis revealed that OGNVs in $\mathrm{H}_{2} \mathrm{O}$ displayed a negative charge of -47.6 $\pm-9.61 \mathrm{mV}$. A NaCl concentration of $155 \mathrm{nM}$ remarkably neutralized the charge of OGNVs to $-3.4 \pm 1.7 \mathrm{mV}$ $(p<0.01)$, but PBS did not change the charge of OGNVs. Taken together, these data suggest that $\mathrm{NaCl}$ treatment of RNA not only increases encapsulation in OGNVs but alters the charge of OGNVs from strongly negative to weakly negative without dramatically affecting the size of the OGNVs.

To further determine whether RNA has been encapsulated in the OGNVs or is located on the surface of OGNVs, OGNVs carrying Exo-GLOW (red) labeled RNA were digested with ribonucleases (RNase). Fluorescence analysis using confocal microscopy revealed RNA was still co-localized with OGNVs after RNase treatment (Supplementary Figure S3D, S3E). Furthermore, without detergent extraction, OGNV RNA was resistant to RNase digestion when OGNVs were kept at $4^{\circ} \mathrm{C}$ for 7 days; whereas after extraction from OGNVs, the RNA 
without encapsulation in OGNVs was degraded by RNase (Supplementary Figure S4). Collectively, these results suggest that potentially therapeutic RNA can be encapsulated into OGNVs. Following this we determined whether UV treatment of OGNVs has an effect on the biological activity of encapsulated RNA. To address this concern, $20 \mu \mathrm{g}$ of luciferase siRNA encapsulated in the OGNVs was transfected into U-87 MG-luc, a luciferase positive glioblastoma cell line which stably expresses the firefly luciferase gene. Assessment of luciferase activity with the Dual-Luciferase Reporter Assay System revealed that a similar activity of luciferase siRNA was demonstrated in the U-87 MG-luc cells transfected with OGNVs (40\%) and polyethylenimine (PEI) (45\%) (Supplementary Figure $\mathrm{S} 3 \mathrm{~F}$ ), a commercial RNA delivery agent.

\section{miR-18a encapsulated in OGNVs (OGNVs-miR- 18a) induces M1 Kupffer cells}

Liver KCs (Figure 1A-1D) but not hepatocytes (Figure 1E) take up OGNVs carrying miR-18a after a tail vein injection. KCs represent $80-90 \%$ of all tissue macrophages in the entire body [37], play a major role in the capture and clearance of foreign material, are important antigen presenting cells (APCs), and express MHC I, MHC II and costimulatory molecules needed for activation of immune cells. Collectively, these features of liver KCs prompted us to test whether GNVs can be used as a vehicle for delivery of therapeutic agents for treatment of liver related disease through the mechanism of immunomodulation of Kupffer cells. Therefore, we set out to determine whether miR-18a delivered by OGNVs has a biological effect on liver metastasis of colon cancer as an example.

OGNV-miR18a treatment, as described in Figure 2A, led to an increase in the percentages of $\mathrm{F} 4 / 80^{+}$ major histocompatibility complex $(\mathrm{MHC}) \mathrm{II}^{+}, \mathrm{F} 4 / 80^{+} \mathrm{IL}-12^{+}$ (M1), F4/80 interferon gamma $(\mathrm{IFN} \gamma)^{+}$and $\mathrm{F} 4 / 80^{+} \mathrm{CD} 80^{+}$ cells (Figure 2B). This increase is specific since the percentages of $\mathrm{F} 4 / 80^{+} \mathrm{CD} 86^{+}$cells present in the liver of tumor bearing mice treated with $\mathrm{OGNVs} / \mathrm{Ctrl}$ alone were no different from those treated with OGNVs-miR18a (Figure 2B). It is well-known that M1 macrophages promote anti-tumor activity whereas M2 macrophages promote tumor progression. We further assessed the M1 versus M2 cytokine expressions in liver $\mathrm{F} 4 / 80^{+}$cells. miR-18a treatment led to increasing percentages of $\mathrm{F} 4 / 80^{+} \mathrm{IFN} \gamma^{+}, \mathrm{F} 4 / 80^{+} \mathrm{IL}-12^{+}, \mathrm{F} 4 / 80^{+} \mathrm{CD} 80^{+}$, and decreasing percentages of $\mathrm{F} 4 / 80^{+}$transforming growth factor beta $(\mathrm{TGF} \beta)^{+}, \mathrm{F} 4 / 80^{+} \mathrm{CD} 206^{+}$and $\mathrm{F} 4 / 80^{+} \mathrm{IL}-10^{+}$detected in the liver metastatic tumor bearing mice (Figure $2 \mathrm{~B}$ ). This result was also supported by the data from quantitative analysis of the proteins expressed on FACS sorted F4/80 KCs (Figure 2C). Consistent with flow cytometry results, OGNV-miR18a treatment dramatically increased the level of genes encoding IFN $\gamma$, IL-12, CD80, inducible nitric oxide synthase (iNOS), and decreased TGF $\beta$ expressed in F4/80 KCs isolated from metastatic liver (Figure 2D). Collectively, miR-18a treatment promoted induction of M1 macrophages (F4/80 ${ }^{+} \mathrm{IFN} \gamma^{+}$and F4/80 IL-12 ${ }^{+}$) with upregulated co-stimulatory factors such as $\mathrm{CD} 80$, and iNOS while inhibiting M2 macrophages (F4/80 $0^{+} \mathrm{TFF} \beta^{+}$, $\left.\mathrm{F} 4 / 80^{+} \mathrm{IL}-10^{+}\right)$in the liver of metastatic colon tumor bearing mice.

The inhibition of liver metastatic tumor growth in CT26 tumor bearing mice treated with OGNV-miR18a was also demonstrated. On day 14 after an intra-splenic injection of CT26 colon tumor cells, the number and size of tumor nodules in the liver of mice treated with vehicle were significantly increased in comparison with mice treated with OGNV-miR18a (Figure 2E). This conclusion is also supported by the fact that there were fewer liver tumor foci, the liver weighed less in OGNV-miR18a treated mice (Figure $2 \mathrm{~F}$ ) and these mice had a significantly prolonged survival (Figure $2 \mathrm{G}$ ).

The induction of M1 macrophages promotes activation of NK, NKT and T cells. The data generated from FACS analysis indicated that at day 2 after OGNVmiR-18a treatment, both $\mathrm{IFN} \gamma^{+} \mathrm{NKT}\left(\mathrm{CD}^{+} \mathrm{DX} 5^{+}\right)$and IFN $\gamma^{+} \mathrm{NK}\left(\mathrm{CD} 3-\mathrm{DX} 5^{+}\right)$but not $\mathrm{T}\left(\mathrm{CD}^{+} \mathrm{DX} 5^{-}\right)$cells were significantly induced; whereas, on day 14 induction of IFN $\gamma^{+} \mathrm{CD}^{+} \mathrm{T}$ cells was dominant (Figure 2H). To further demonstrate the role of macrophage-derived IL12 induction of IFN $\gamma^{+} \mathrm{NK}$ and IFN $\gamma^{+} \mathrm{NKT}$, mice treated with OGNVs co-encapsulating miR-18a and IL-12 siRNA but not encapsulating IL-12 siRNA alone resulted in significant reduction of liver IFN $\gamma^{+} \mathrm{NK}$ and IFN $\gamma^{+} \mathrm{NKT}$, but had no effect on IFN $\gamma^{+} \mathrm{CD} 3^{+} \mathrm{DX} 5^{-} \mathrm{T}$ cells (Figure 3 ). Consistent with in vivo results, neutralizing IL-12 in the supernatants of miR-18a pre-transfected IL-12 ${ }^{+}$RAW264.7 macrophage-like cells (Supplementary Figure S5) co-cultured with primary spleen NKT cells led to a significant reduction of IFN $\gamma$ expressed in the NKT cells (Supplementary Figure S5). Collectively, these results suggest that F4/80 $\mathrm{IL}-12^{+}$cells induced by OGNV-miR18 a plays a crucial role in the inhibition of liver metastasis of colon cancer.

\section{Liver macrophages play a dominate role in inhibition of colon tumor metastasis in the liver}

To identify whether the anti-tumor activity of miR18 a was directly mediated by liver macrophages, mice were repeatedly treated with clodronate liposome as described in Figure 4A to deplete macrophages before an intra-splenic injection of CT26 cells. Depletion of macrophages (Figure 4B, 4C) abolished the anti-tumor activity of miR-18a, and the miR-18a-mediated anti-tumor activity was restored by adoptive transfer of macrophagelike RAW264.7 cells (Figure 4D). This conclusion is also supported by the significant induction of liver IFN $\gamma^{+} \mathrm{NKT}$ and IFN $\gamma^{+} \mathrm{NK}$ cells at day 2 and IFN $\gamma^{+} \mathrm{CD}^{+} \mathrm{T}$ cells on day 
14 after RAW264.7 cells were adoptively transferred into macrophage depleted mice (Figure 4E).

\section{miR-18a-mediated inhibition of the growth of liver metastasis of colon tumor cells is IFN $\gamma$ dependent}

To determine whether the effect of miR-18a against liver metastasis of colon cancer results from induction of $\mathrm{KC}$ IFN $\gamma$, CT26 colon carcinoma cells were intra-splenic injected into IFN $\gamma$ knock out (KO) mice. On day 14 after tumor cell inoculation, OGNVs/miR-18a treatment showed no evidence of inhibiting tumor growth in IFN $\gamma$ $\mathrm{KO}$ mice. Mice treated with OGNVs/control (Ctrl)miRNA alone and OGNVs/miR18a were similar in liver size and weight (Figure 5A). The H \& E stained sections of liver from both groups displayed similar pathology of liver metastasis (Figure 5A). As expected, IFN $\gamma$ expression was not found on leukocytes or F4/80 cells from the livers

A

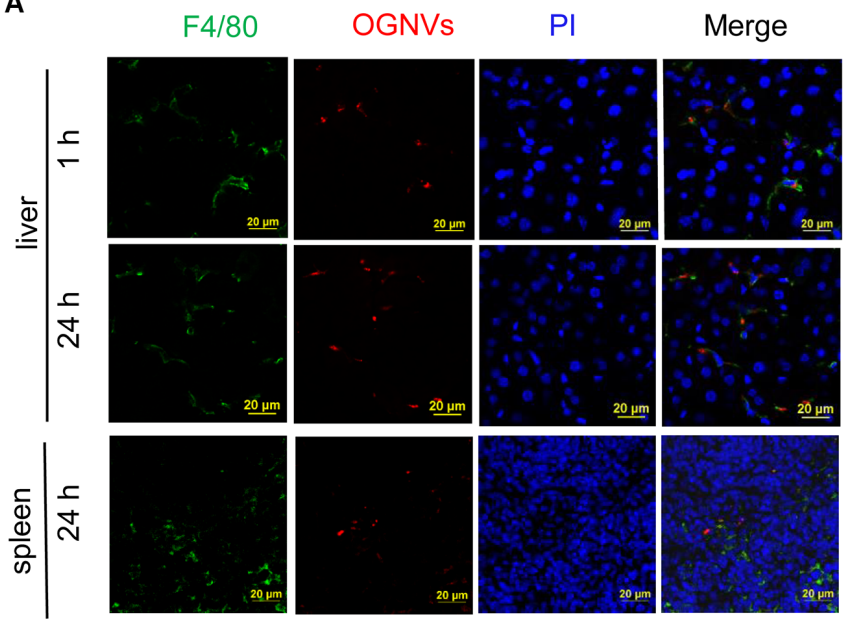

in IFN $\gamma \mathrm{KO}$ mice (Figure 5B). Evidence for the effect of miR-18a on induction of F4/80 $\mathrm{IL}-12^{+}$was not obtained in IFN $\gamma \mathrm{KO}$ mice although the expression of TGF $\beta$ was still repressed by miR-18a (Figure 5C). Collectively, these results indicate that $\mathrm{KC} I F N \gamma$ is an upstream cytokine of IL12 for miR-18a mediated induction of M1 macrophages. $\mathrm{KC} \mathrm{IFN} \gamma$ is required for miR-18a-mediated induction of IL-12. Induction of macrophage IL-12 further enhances activation of NK and NKT cells at positive feed-back manner. To further clarify the role of NK, NKT and T cells on the inhibition of tumor metastasis caused by miR-18a, NOG mice which are deficient for NK, NKT, and T cells were challenged with CT26 tumor cells using the identical protocol described for induction of liver metastasis of colon cancer in a wild-type BALB/c mouse model (Figure 2). As expected, multi-administration of OGNVs-miR-18a did not lead to inhibition of tumor metastasis in the NOG mice (Figure 5D) although $\mathrm{F} 4 / 80^{+} \mathrm{IFN}^{+}$, F4/80 ${ }^{+} \mathrm{IL}-12^{+}$and $\mathrm{F} 4 / 80^{+} \mathrm{MHCII}^{+}$cells

B

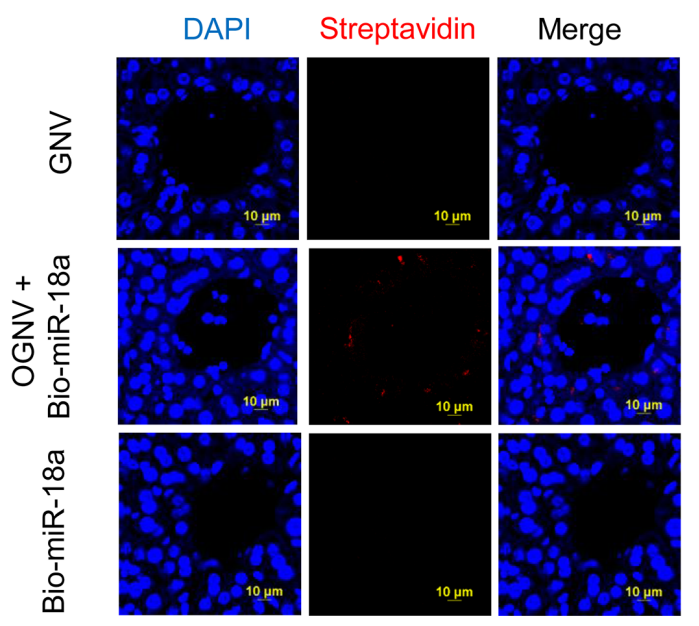

C

$\mathrm{Oh}$

$1 \mathrm{~h}$

$24 \mathrm{~h}$

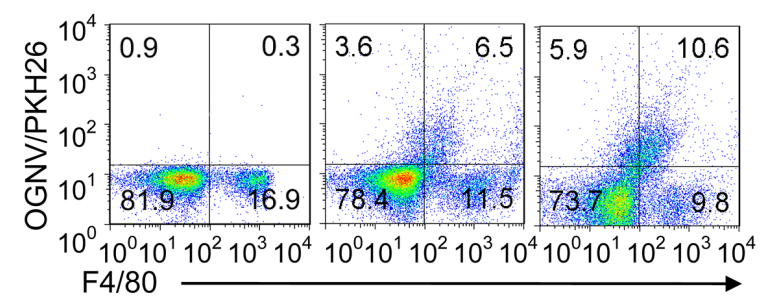

D

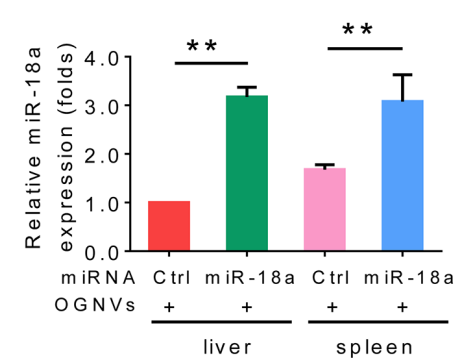

E

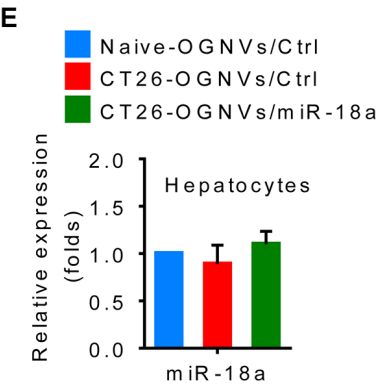

Figure 1: OGNV-mediated delivery of miRNA is taken up by mouse Kupffer cells in vivo. (A) PKH26-labeled (red) OGNVs

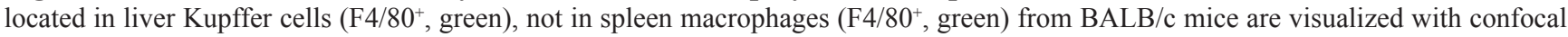
microscopy, assessed $1 \mathrm{~h}$ and $24 \mathrm{~h}$ after intravenous injection. (B) Analysis of Alexa Fluor fluorescent streptavidin conjugates with confocal microscope, assessed $24 \mathrm{~h}$ after intravenous injection of OGNVs alone, OGNVs with biotin-conjugated miR-18a (bio-miR-18a), or biomiR-18a alone. (C) Frequency of F4/80 cells and PKH26-labled OGNVs in the liver from BALB/c mice assessed using flow cytometry. Numbers in quadrants indicate percent cells in each. (D) Quantification of miR-18a level in leukocytes from BALB/c mouse liver and spleen assessed $24 \mathrm{~h}$ after intravenous injection of OGNVs with miR-18a by quantitative real-time PCR (qPCR). $* P<0.05$ and $* * P<0.01$ (two-tailed $t$-test). Data are representative of three independent experiments (error bars, S.E.M.). (E) Expression of miR-18a in hepatocytes from naive BALB/c mice, CT26 liver metastasis mice with OGNVs/Ctrl or OGNVs/miR-18a treatment assessed by quantitative real-time PCR (qPCR). 
A

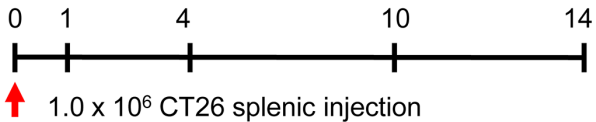

OGNVs/miR-18a (2 nM)

or control miRNA

Data collection

4 i.v. 3 times
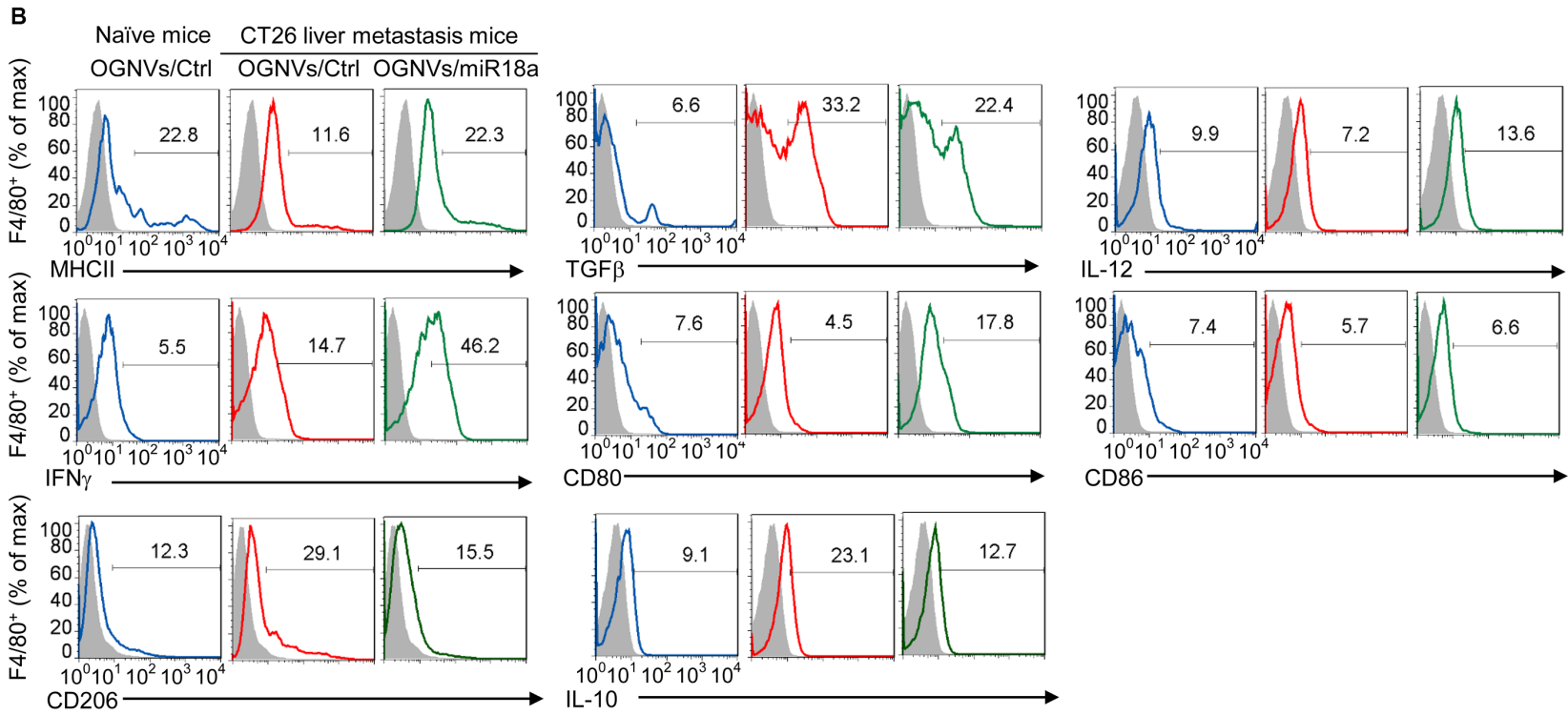

$10^{0} 10^{1} 10^{2} 10^{3} 10^{2}$

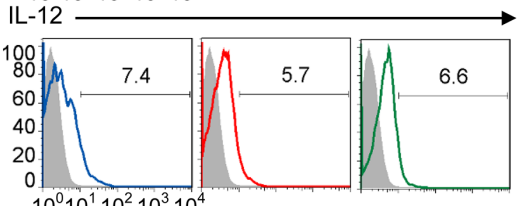

$10^{0} 10^{1} 10^{2} 10^{3} 10^{4}$

$10^{0} 10^{1} 10^{2} 10^{3} 10^{4}$

CD86

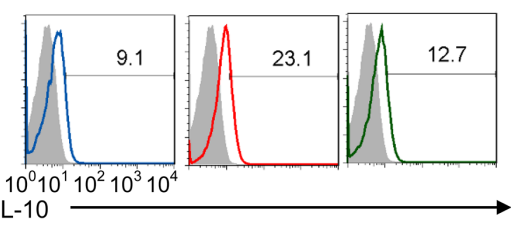

Liver metas-OGNVs/C trl

Liver metas-OGNVs/miR-18a

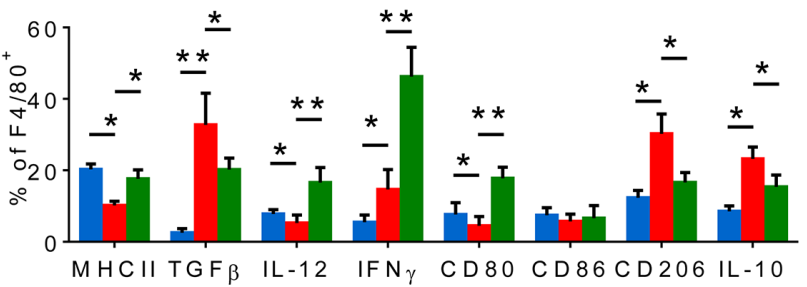

D
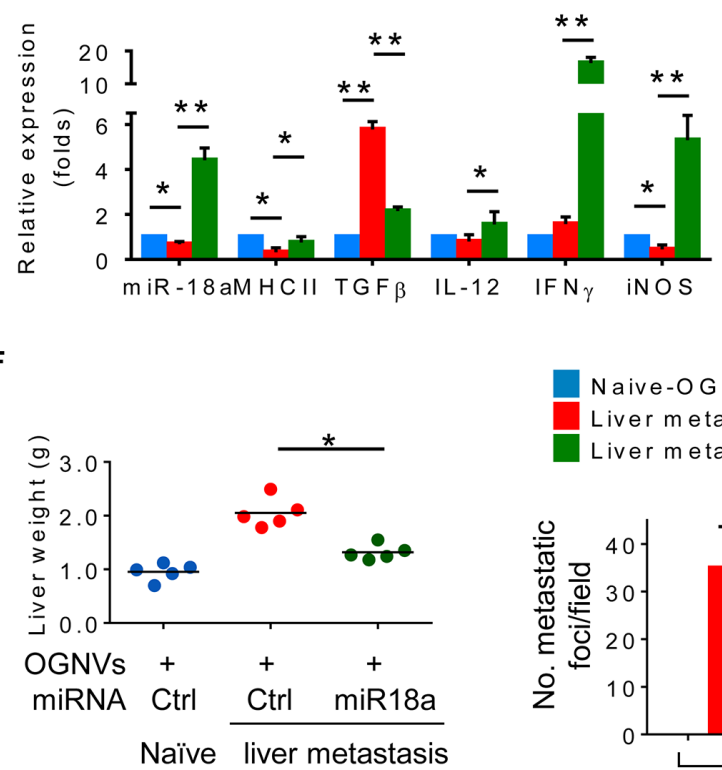

E

Naïve mice CT26 liver metastasis mice OGNVs/Ctrl OGNVs/Ctrl OGNVs/miR18a

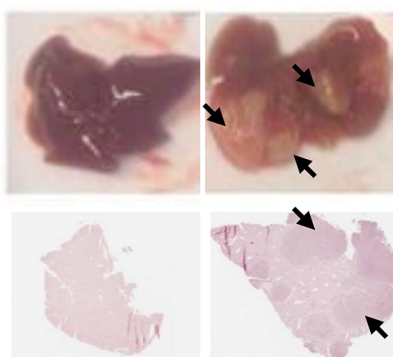

$400 x$

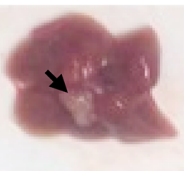

$20 x$
$\mathrm{N}$ aive-OGNVs/Ctrl

Liver metas-OGNVs/C trl

Liver metas-OGNVs/miR-18a

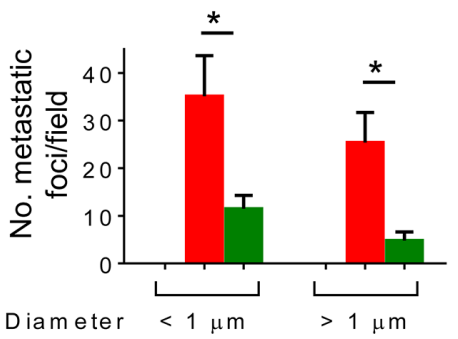

G

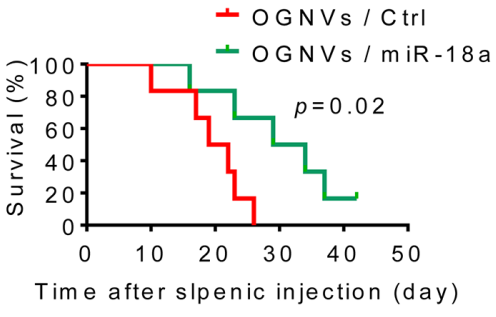



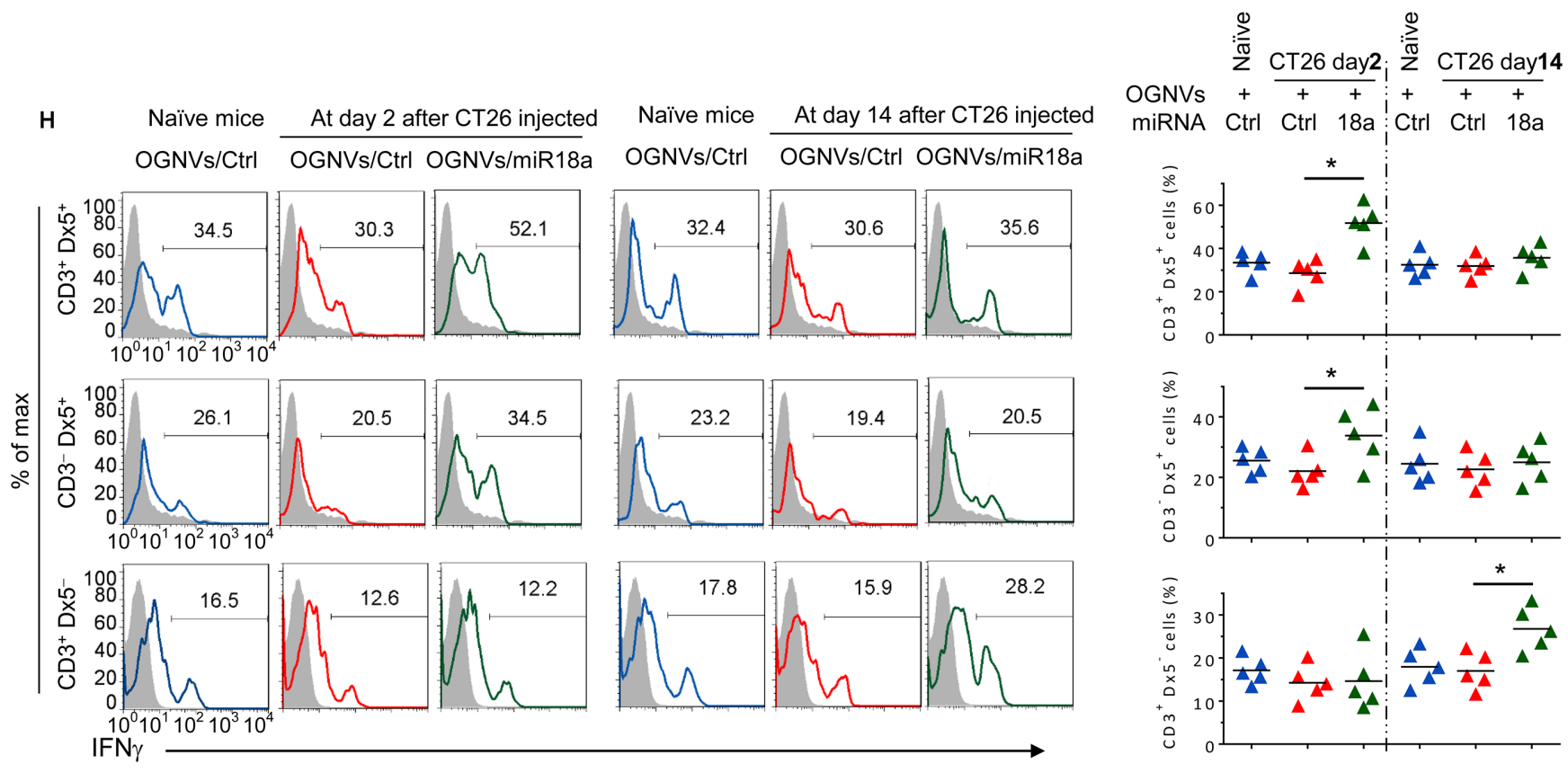

Figure 2: miR-18a encapsulated in OGNVs inhibits liver metastasis of colon cancer and induces Kupffer cell polarization into M1. (A) Schematic representation of the treatment schedule. All groups of mice were euthanized 14 days after the intra-splenic tumor inoculation, and tumor specimens were obtained for analysis. (B) Frequency of MHCII, TGF $\beta$, IL-12, IFN $\gamma$, CD80, CD86, CD206, and IL-10 positive cells in liver F4/80 cells from naive BALB/c mice, CT26 liver metastasis mice treated with OGNVs packing control miRNA (OGNVs/Ctrl) or OGNVs packing miR-18a (OGNVs/miR-18a) assessed by flow cytometry. (C) The histogram shows the quantification of results at (b). (D) Expression of mature miR-18a, MHCII, TGF $\beta$, IL-12, IFN $\gamma$, and iNOS in liver F4/80 $0^{+}$cells was assessed by qPCR. (E) Representative livers (up) and representative hematoxylin and eosin (H \& E)-stained sections of livers (middle, 20×; bottom, 400× magnification). (F) Liver weight (left) and liver metastatic nodule number and size (right). (G) Survival of mice after intra-splenic injection of CT26 cells. (H) Frequency of IFN $\gamma^{+}$cells in liver $\mathrm{CD}^{+} \mathrm{Dx} 5^{+}(\mathrm{NKT})$ cells, $\mathrm{CD} 3{ }^{-} \mathrm{Dx} 5^{+}(\mathrm{NK})$ cells, and $\mathrm{CD} 3^{+} \mathrm{Dx} 5^{-}$ (T) cells. Right, quantification of results; each symbol represents an individual mouse. ${ }^{*} P<0.05$ (two-tailed $t$-test). Data are representative of three independent experiments (error bars, S.E.M.).
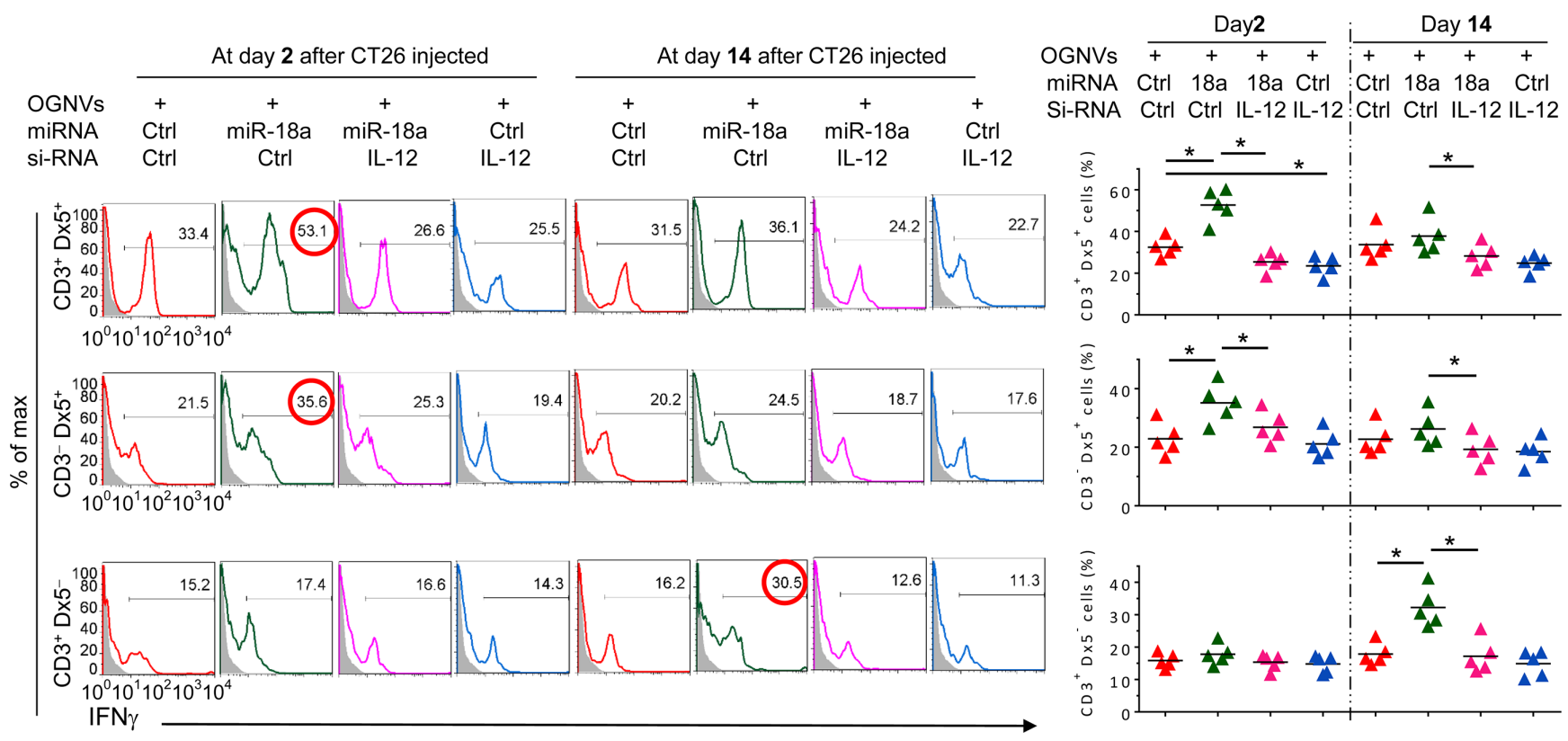

Figure 3: Induction of IFN $\boldsymbol{\gamma}^{+} \mathbf{N K}$ and IFN $\boldsymbol{\gamma}^{+} \mathrm{NKT}$ by OGNVs-miR-18a. Frequency of IFN $\gamma^{+}$cells in liver $\mathrm{CD} 3^{+} \mathrm{Dx} 5^{+}(\mathrm{NKT})$ cells, $\mathrm{CD}^{-}{ }^{-} \mathrm{Dx} 5^{+}(\mathrm{NK})$ cells, and $\mathrm{CD}^{+}{ }^{+} \mathrm{Dx} 5^{-}$(T) cells from CT26 liver metastasis mice treated with OGNVs-Ctrl, OGNVs-miR-18a with/without IL-12 siRNA knockdown assessed by flow cytometry (Left); Right, quantification of FACS analyzed results; each symbol represents an individual mouse. 
A
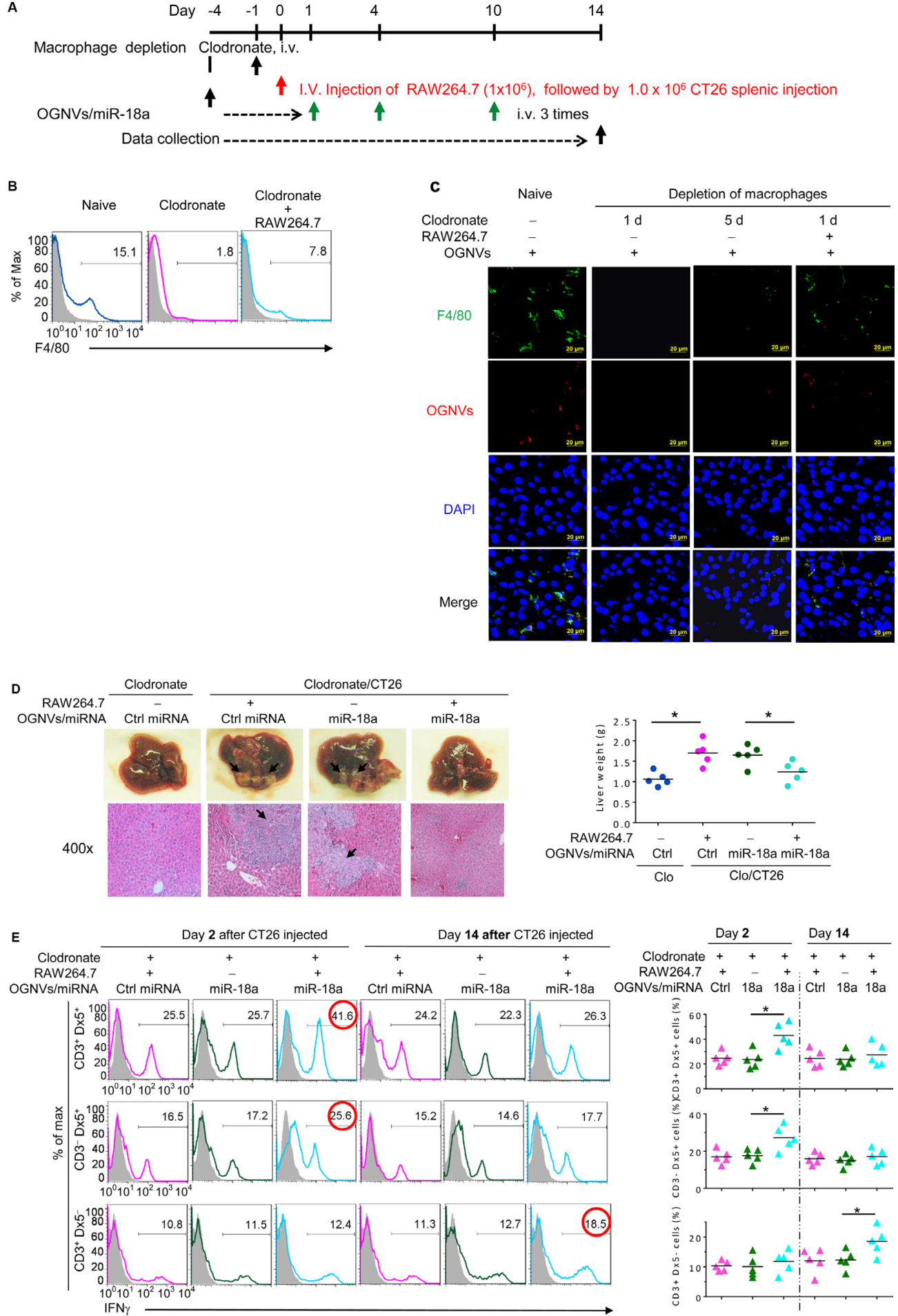

Figure 4: Depletion of macrophages restricted the response of miR-18a against liver metastasis. (A) Schematic representation of treatment schedule. All groups of mice were euthanized 14 days after the intra-splenic tumor injection, and tumor specimens were obtained for analysis. (B) Frequency of $\mathrm{F} 4 / 80^{+}$cells in liver leukocytes from clodronate treated $(110 \mathrm{mg} / \mathrm{kg}) \mathrm{mice}$, with or without RAW264.7 cells assessed by flow cytometry. (C) PKH26-labeled (red) OGNVs located in liver Kupffer cells (F4/80', green) were visualized with confocal microscopy at $1 \mathrm{~d}$ and $5 \mathrm{~d}$ after administer of clodronate. Data are representative of three independent experiments. (D) Representative for the treatment effect on liver metastasis (left, upper panel) and hematoxylin and eosin (H \& E)-stained liver sections (left bottom panel) from Kupffer cell depleted mice with or without RAW264.7 cells adoptively transferred, Right; Liver weight. (E) Frequency of IFN $\gamma$ positive cells (left panel) in liver $\mathrm{CD}^{+}{ }^{+} \mathrm{Dx} 5^{+}(\mathrm{NKT})$ cells, $\mathrm{CD}^{-} \mathrm{Dx} 5^{+}(\mathrm{NK})$ cells, and $\mathrm{CD}^{+} \mathrm{Dx} 5^{-}$(T) cells from OGNVs/ Ctrl miRNA and OGNVs/miR-18a treated mice with/without macrophages pre-depleted. The percentages of positive NK, NKT, and T cells are shown (right panel); each symbol represents an individual mouse. ${ }^{*} P<0.05$ (two-tailed $t$-test). Data are representative of three independent experiments (error bars, S.E.M). 
(Figure 5E) were still induced. The fact that the frequency of $\mathrm{CD}^{+}$and $\mathrm{Dx} 5^{+}$cells were undetectable in naïve or tumor bearing NOG mice (Supplementary Figure S6) regardless of treatment supports the idea that NK, NKT, or $\mathrm{T}$ cells are effector cells responsible for inhibition of liver metastasis of colon cancer cells. In contrast, the data generated from nude mice (Figure 5F) which have both NK and NKT cell activity suggest that NK and NKT cells play a critical role in the inhibition of tumor metastasis caused by miR-18a. The effects of miR-18a on induction on IFN $\gamma^{+} \mathrm{IL}-12^{+} \mathrm{KCs}$ (Figure $5 \mathrm{G}$ ) and IFN $\gamma^{+} \mathrm{NK}^{+}$cells (Figure $5 \mathrm{H}$ ) has no impact in $\mathrm{T}$ cell deficient nude mice. In combination with data generated from macrophage depletion, IFN $\gamma \mathrm{KO}$ mice and NOG and nude mice, these data suggest that miR-18a delivered by OGNVs initially induces expression of IFN $\gamma$ in macrophages, which is required for induction of macrophage IL-12. Subsequently, macrophage IL-12 amplifies the miR-18a-mediated antitumor activity by activation of liver NK and NKT cells in an IFN $\gamma$ dependent manner.

\section{miR-18a suppresses liver metastasis of colon cancer triggered by directly targeting IRF2}

Given the profound anti-colon tumor metastasis effect of miR-18a delivered by OGNVs, how miR-18a induces the expression of IFN $\gamma$ in macrophages required further investigated. We first searched miRNA databases for potential miR-18a targets that may possibly contribute to IFN $\gamma$ induction. The three public miRNA databases (TargetScan, Pictar, and MicroRNA) all predicted that $\operatorname{Irf} 2$ might be a target for miR-18a; the 3'-UTR of $\operatorname{Irf} 2$ contains a highly conserved binding site from position 1668 to 1682 for miR-18a (Figure 6A). To determine whether miR-18a could target $\operatorname{Irf} 2$ in macrophage cells, we transfected the mouse mature miR-18a mimic into BALB/c-derived macrophage-like RAW264.7 cells. The RAW264.7 cells transfected with OGNVs/miR-18a have significantly down-regulated IRF2 mRNA expression (Figure 6B) as well as IRF2 protein expression (Figure 6C, 6D). We also found IFN $\gamma$ induction by OGNVs/miR-18a following reduction of $\operatorname{Irf} 2$ (Figure 6C). Irf2 siRNA repressed $\operatorname{Irf} 2$ expression in RAW264.7 cells and led to increasing IFN $\gamma$ expression (Figure 6E, 6F). These in vitro results were further confirmed in the liver $\mathrm{KCs}$ isolated from liver metastasis in CT26 mice administrated OGNVs/miR-18a (Figure 6G). To ascertain the direct effect of miR-18a on $\operatorname{Irf} 2$, a mutant construct that would disrupt the predicted miR-18a binding site was generated from pEZX-MT01Irf 2 containing a 1,234 bp length 3'UTR of Irf2 mRNA (Gene Accession: NM_008391.4). We performed a luciferase reporter assay by co-transfecting a vector containing IRF2 3'UTR fused luciferase and miR-18a or control miRNA as a negative control. Overexpression of miR-18a decreased the luciferase activity of the reporter with 3'UTR of Irf2 by about $60 \%$ in RAW264.7 cells
(Figure 6H). However, mutation that disrupted the binding site for miR-18a entirely restored luciferase activity. Moreover, overexpression of anti-sense (AS) miR-18a caused induction of luciferase and no inductive effect of AS-miR-18a on the activity of the reporter when a mutant 3'UTR of $\operatorname{Irf} 2$ was detected. These results demonstrate that Irf2 is a target of miR-18a in macrophages.

We further determined whether the $\operatorname{Irf} 2$ was upregulated in the metastatic liver tissue of colon cancer patients. The results from immunohistological staining of CD68 and IRF2 in human liver sections (Figure 7) suggest that IRF2 is expressed in liver CD68 macrophages. More importantly, the levels of expression of IRF2 in the liver of human colon metastatic patients are increased as the disease progresses. These results indicated that IRF2 expression correlates with liver metastasis differentiation in colorectal cancer.

\section{DISCUSSION}

Liver metastases are common in many types of cancer, especially those of the gastrointestinal tract, breast, lung, and pancreas. Most treatments are not effective for liver metastasis because liver metastases represent cancer that has spread from another part of the body. We hypothesize that boosting the strength of anti-tumor immune responses may be a better way to treat liver metastasis; in particular, creating a liver microenvironment that is dominated by anti-tumor M1 macrophages.

In this study, our main finding is highlighted in a novel regulatory mechanism of M1 macrophage functioning along the IFN- $\gamma / \operatorname{Irf} 2$ axis mediated by miR18a (Supplementary Figure S7). These findings establish a proof of concept and the basis for treating liver metastasis of colon cancer by mediating macrophage populations which in turn could be applicable to other types of cancers and macrophage-mediated inflammatory diseases.

Liver macrophages are not only pleiotropic cells that can function as immune effectors and regulators, tissue remodelers, or scavengers [38], but also have unique location. KCs are stationary cells located in the vasculature, adherent to liver sinusoidal endothelial cells (LSECs) and directly exposed to the contents of blood. This is in contrast to other monocyte and macrophage cell populations located in other tissues that actively crawl through the tissue in search of pathogens or nano/micro particles. Importantly, the size of most nanoparticles, including GNVs, makes them favorable to being trapped in the liver. In addition, KCs represent $80-90 \%$ of all tissue macrophages in the entire body [39]. Collectively, these KCs features made GNVs favorable homing to the liver. The data presented in this study suggest that liver macrophages are preferentially targeted by GNV, and miR-18a delivered by GNVs to promote liver anti-tumor M1 macrophages induction. Since the liver is one of the major organs involved in metastasis for a number of different types of cancers, including colon 
A

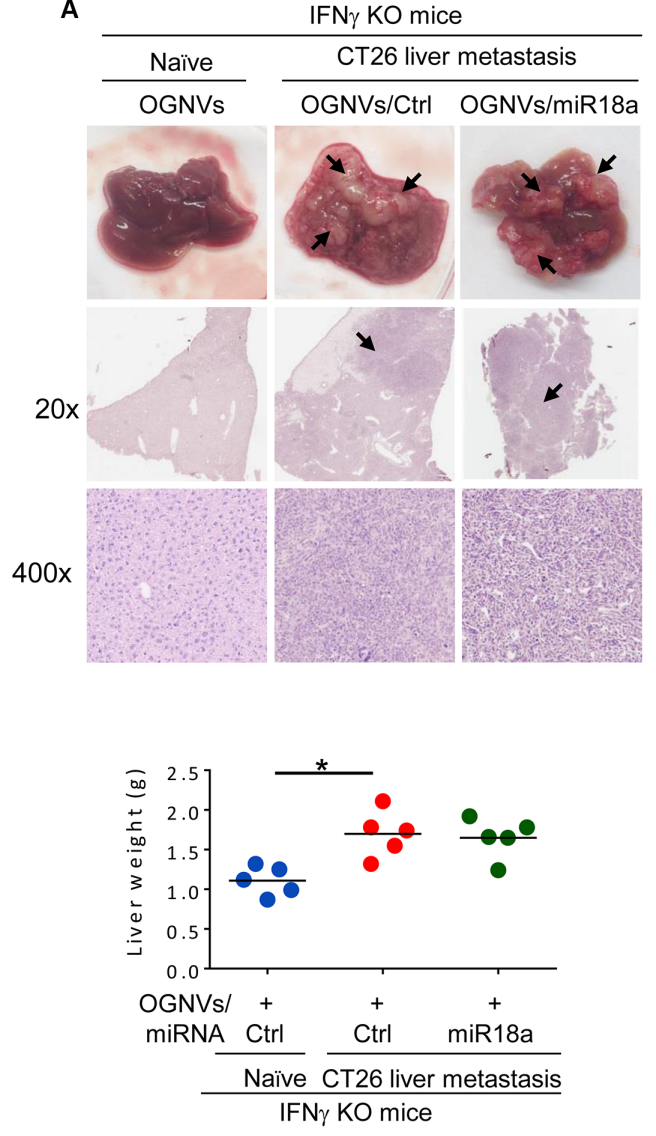

D
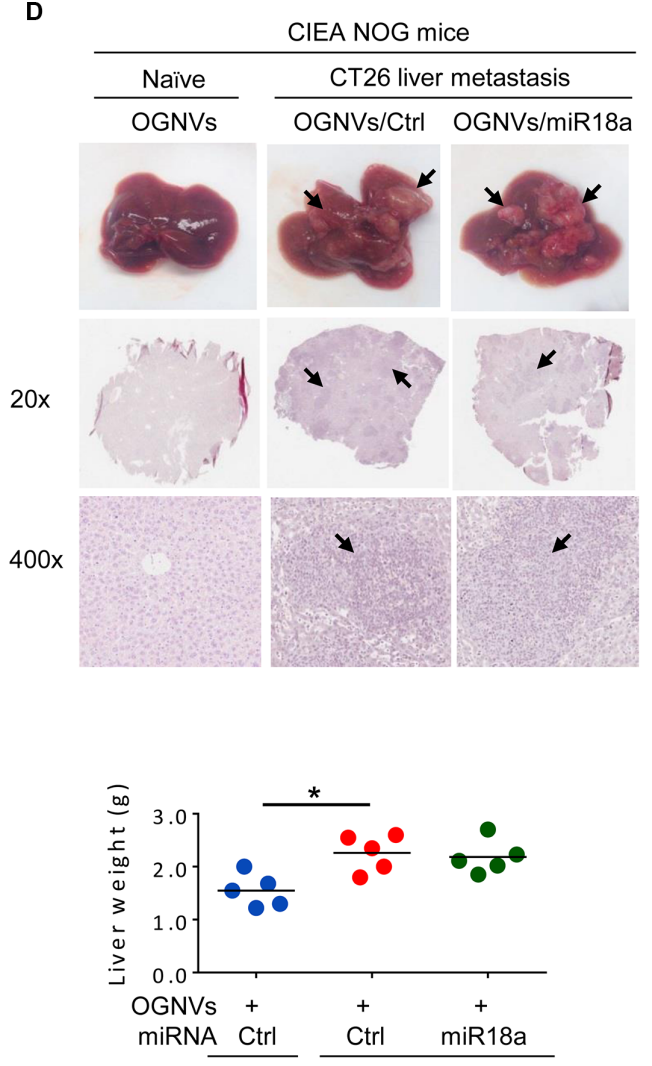

Naive CT26 liver metastasis CIEA NOG mice
B

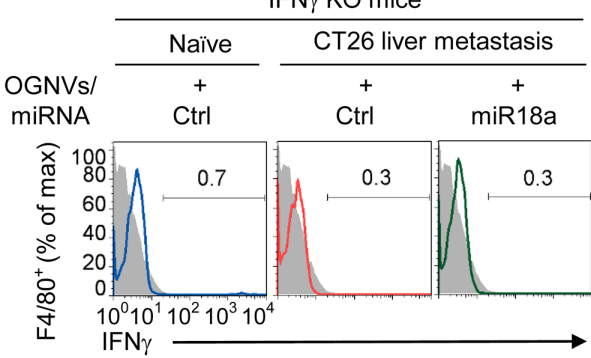

C

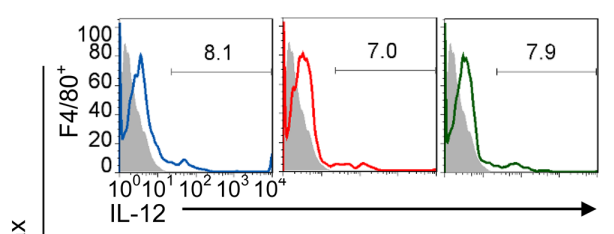

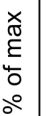
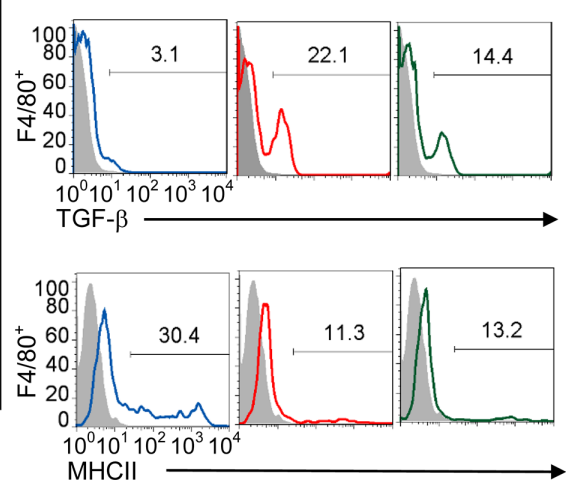

E
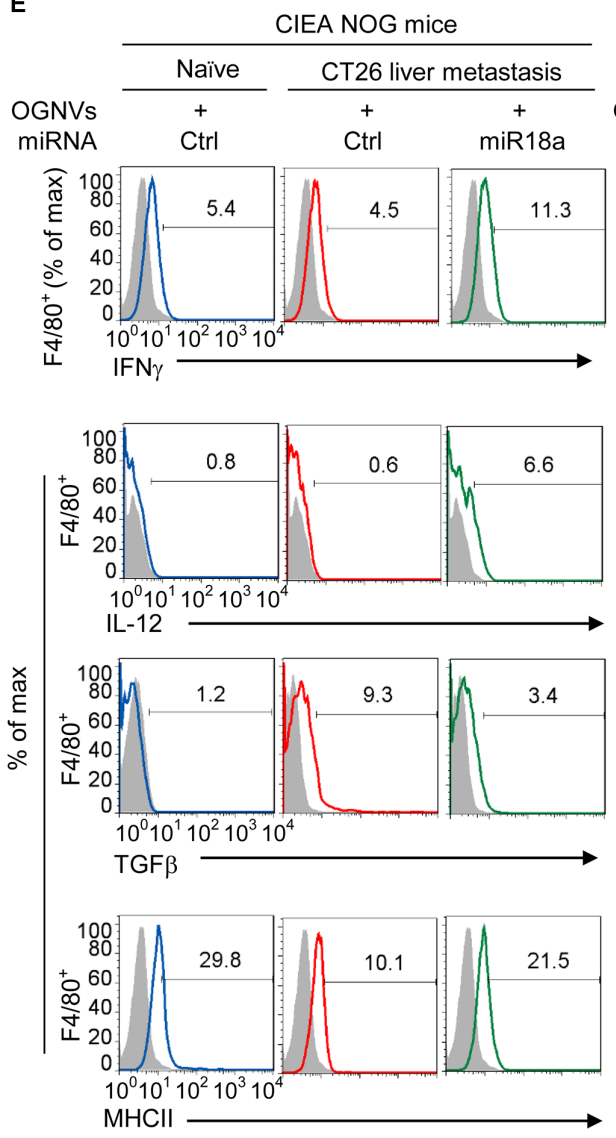
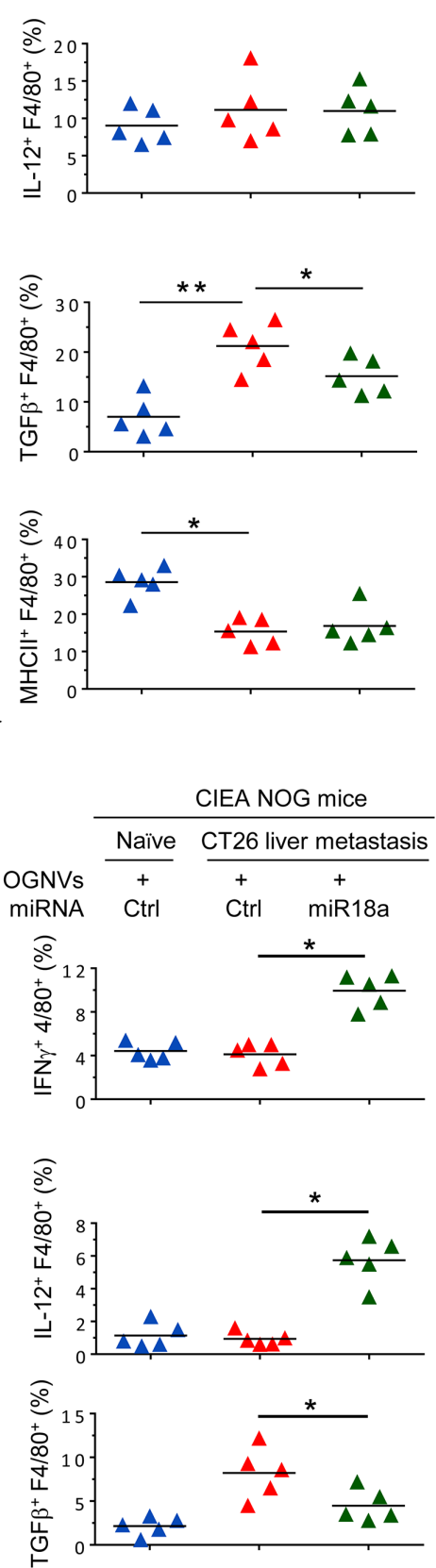

CIEA NOG mice

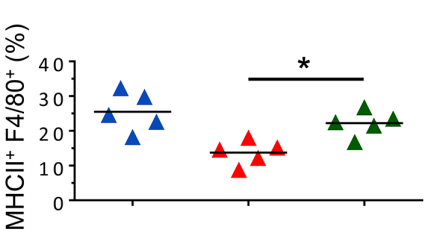


F
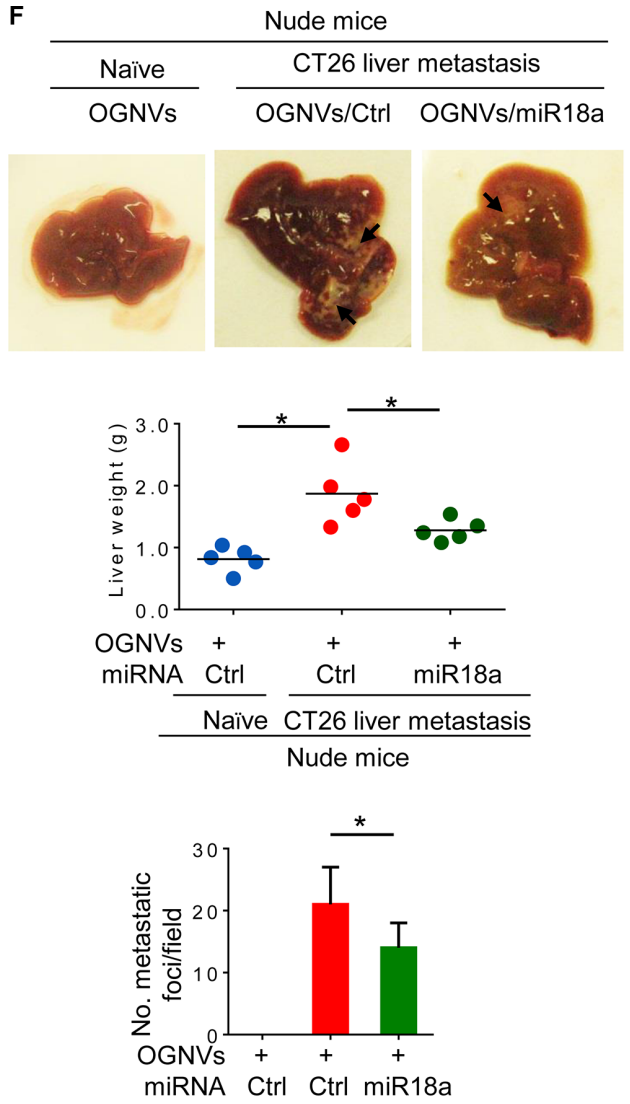

Naïve liver metastasis
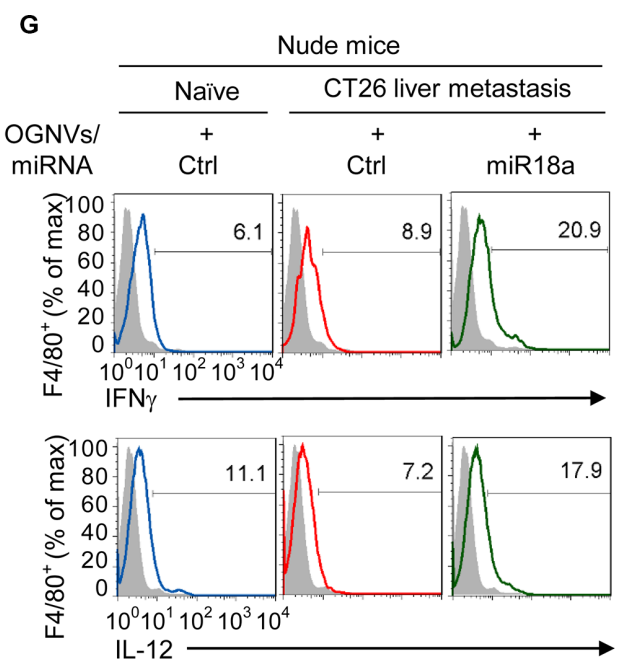

H

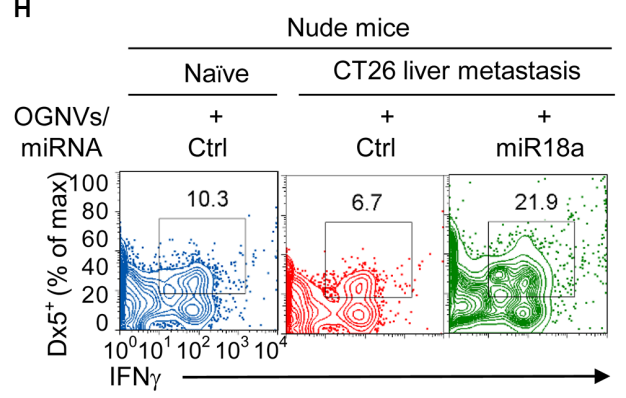

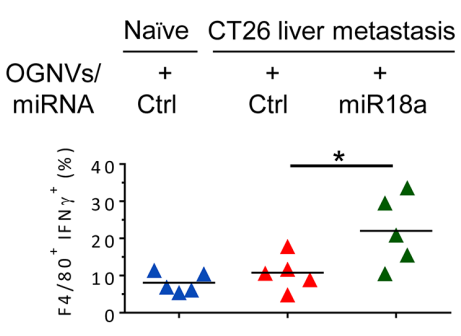

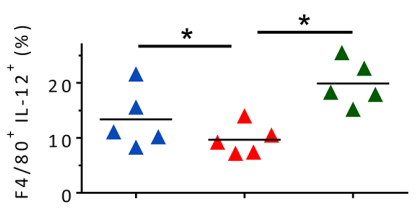

Nude mice

Figure 5: miR-18a mediated inhibition of the growth of liver metastasis of colon tumor cells is IFN $\gamma$ dependent. (A) Representative livers (up) (metastatic nodules shown by arrows) and H \& E-stained sections of livers (middle, 20×; bottom, 400× magnification) from IFN $\gamma$ knockout (KO) naïve mice. Liver weight of IFN $\gamma \mathrm{KO}$ mice (bottom). (B) Frequency of IFN $\gamma^{+} \mathrm{F} 4 / 80^{+}$cells in liver from IFN $\gamma \mathrm{KO}$ mice (Naïve) and CT26 liver metastatic mice was assessed by flow cytometry. The percentages of IFN $\gamma+\mathrm{F} 4 / 80+$ cells in liver and each symbol represents the FACS data from individual mice (right panel). (C) Frequency of IL-12, TGF $\beta$, MHCII positive cells in liver $\mathrm{F} 4 / 80^{+}$cells from IFN $\gamma \mathrm{KO}$ mice was assessed by flow cytometry. The percentages of double positively stained cells from treated mice are presented, and each symbol represents the FACS data from individual mice (right panel). (D) Representative livers (upper) and H\&E-stained sections of livers (middle, 20x; bottom, 400x magnification) from NOG mice treated as labeled in the figure are shown (upper panel), and liver weight of NOG mice treated as labeled in the figure is indicated (bottom panel). (E) Frequency of liver F4/80 IFN $\gamma^{+}$, $\mathrm{F} 4 / 80^{+} \mathrm{IL}-12^{+}, \mathrm{F} 4 / 80^{+} \mathrm{MHCII}^{+}$and F4/80 ${ }^{+} \mathrm{TGF}^{+}$cells from NOG mice treated as indicated in the labels of figure 5e. Percent double positive cells (right panels). (F) Representative livers (up) from athymic nude mice. Middle: liver weight. Bottom: quantification of liver metastatic foci. (G) Frequency of IFN $\gamma$ and IL-12 positive cells in liver F4/80 $\mathrm{KC}$ cells. (H) Frequency of IFN $\gamma$ positive cells in liver Dx $5^{+} \mathrm{NK}$ cells. $* P<0.05$ (two-tailed $t$-test). Data are representative of three independent experiments (error bars, S.E.M.).

cancer, and M1 macrophages play a role in an anti-tumor progression in general, our strategy could also be applied to treat other types of cancer with liver metastasis.

The acute inflammatory response is characterized by the presence of liver M1 macrophages, and the chronic or resolution of inflammatory phases is mediated by the enrichment of M2 macrophages. M1 macrophages are known to enhance anti-tumor growth and microbial clearance, and M2 macrophages are known to enhance liver tissue repair and to secrete pro-resolution substances including TGF- $\beta$. Therefore, targeted delivery of specific therapeutic agents which can modulate polarization of liver macrophages is critical. Our data presented in this study indicate that OGNVs are taken up by liver macrophages. The data we recently published $[40,41]$ and present in this study (Supplementary Figure S8) suggest that unlike commercially available vectors, OGNVs are non-toxic to the macrophages and liver and can be easily produced on a large scale basis for clinical applications and are capable of delivering a variety of different types of therapeutic agents.

In this study, we further optimized the conditions for OGNV delivery of mRNAs and miRNAs. Therefore, without manipulation of the OGNV, such as adding a targeting moiety, therapeutic agents delivered by OGNVs automatically get into liver macrophages with no toxic effects. 
A

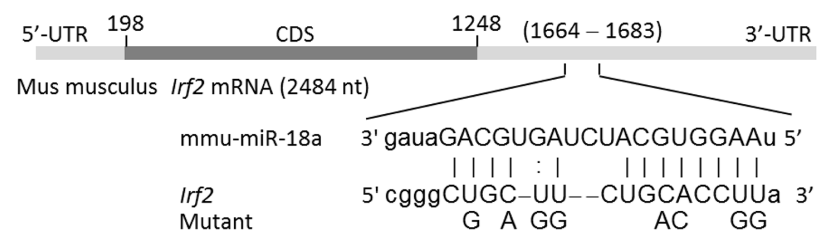

B

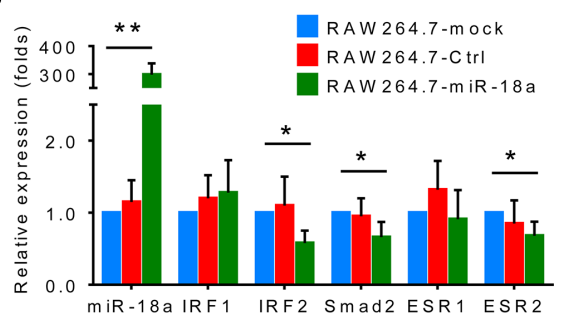

C

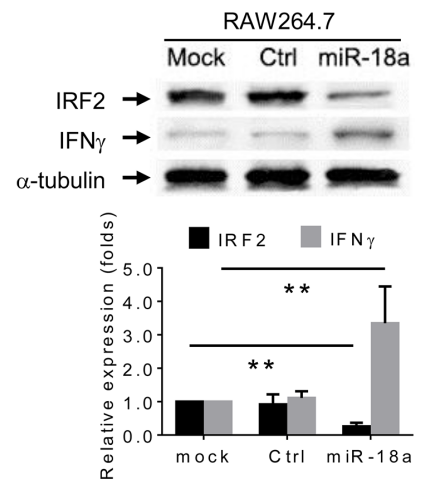

E

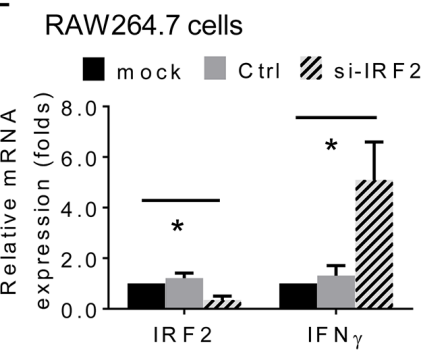

G

Kupffer cells from BALB/c

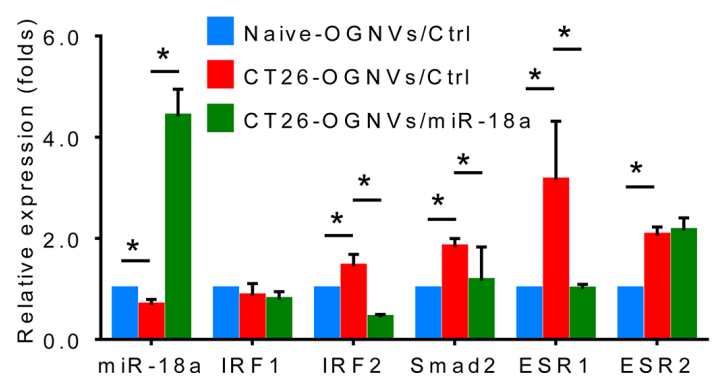

D
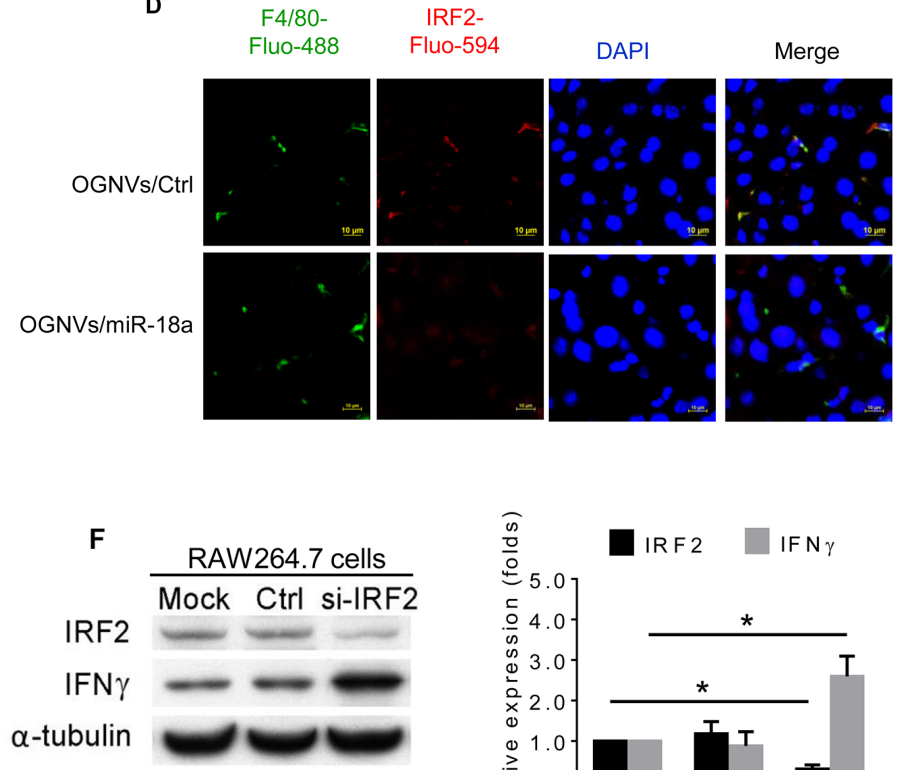

H

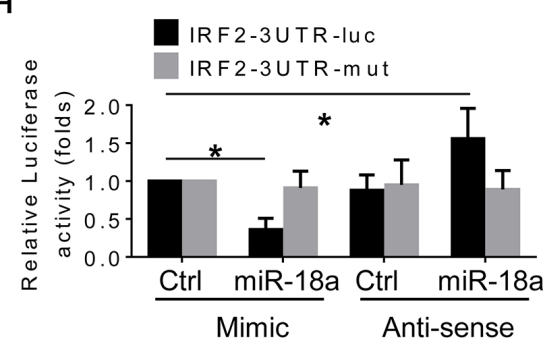

Figure 6: miR-18a suppresses liver metastasis of colon cancer triggered by direct targeting of Irf2 expressed in Kupffer cells. (A) Schematic diagram of the putative binding sites of miR-18a in the wide type (WT) IRF2 3' untranslated regions (UTR). The miR-18a seed matches in the IRF2 3'UTR are mutated at the positions as indicated. CDS, coding sequence. (B) Expression of miR-18a and potential miR-18a targeted genes in macrophages-like RAW264.7 cells was analyzed by real-time PCR. (C) Expression of candidate miRN18a target gene IRF2 and IFN $\gamma$ in macrophage RAW264.7 cells assessed by western blotting. (D) IRF2 (red) expression in liver of CT26/ OGNVs and CT26/OGNVs/miR-18a treated mice, visualized with a confocal microscopy. Data are representative of three independent experiments $(n=5$ ). (E) Evaluation of IRF2 and IFN $\gamma$ level in macrophage-like RAW264.7 cells assessed by qPCR, $72 \mathrm{~h}$ after transfection of IRF2 siRNA (si-IRF2) or control (Ctrl) siRNA. (F) Expression of IRF2 and IFN $\gamma$ in aliquots of macrophage-like RAW264.7 cells assessed by western blotting (left), quantification of results (right). (G) Expression of miR-18a and candidate miR-18a target genes in liver F4 $/ 80^{+}$cells sorted by FACS and assessed by real-time PCR, following intravenous administration of OGNVs/miR-18a mimic and OGNVs/ control miRNA. (H) Luciferase activity assays of WT and mutated Irf2 3'UTR luciferase reporters after co-transfection with miR-18a mimic, miRNA mimic control, miR-18a anti-sense RNA (AS-miR-18a), or miRNA anti-sense negative control RNA in RAW264.7 cells. The luciferase activity of each sample was normalized to the Renilla luciferase activity. The normalized luciferase activity of transfected control mimic miRNA was set as relative luciferase activity of 1. Error bars represent S.E.M. Each data point was measured in triplicate. 
Different microRNAs are expressed in M1 or M2 macrophages and have been shown to control macrophage polarization. The role of miR-18a in macrophage polarization is unknown but immunomodulation of dendritic cell function of miR-18a has been described [42, 43]. We found that liver macrophages are polarized to M1 macrophages after miR-18a is delivered by OGNVs. The molecular mechanisms involved in miR-18a-induced M1 macrophages were further studied and we found that miR-18a-mediated induction of macrophage IFN $\gamma$ is required for inhibition of liver metastasis of colon cancer and that macrophage IRF2 is targeted by miR-18a.

Unlike the situation with artificially synthesized nanoparticles, recently, we have developed grapefruitderived nanovectors (GNVs) which can deliver a variety of therapeutic agents including chemotherapeutic compounds, DNA expression vectors, siRNA and proteins such as antibodies [41]. GNVs have a number of advantages over other delivery systems, including low toxicity, large scale production with low cost, and easily biodegradable without biohazards to the environment. However optimization of GNVs to maximize carrying therapeutic agents has not been studied. In this study, using miR-18a as an example, we found that optimized GNVs (OGNVs) are capable of encapsulating miR-18a and the ability was significantly increased by short pre-exposure of the GNVs mixed with
miR-18a buffered with an optimized concentration of $\mathrm{Na}^{+}$with exposure to ultraviolet (UV) light. We further demonstrate that miR-18a delivered by GNVs inhibits the growth of colon tumors that have metastasized to the liver by polarizing $\mathrm{KCs}$ to $\mathrm{M} 1$ cells $\left(\mathrm{F} 4 / 80^{+} \mathrm{IFN} \gamma^{+} \mathrm{IL}-12^{+}\right)$. miR-18a mediated induction of $\mathrm{M} 1 \mathrm{IFN} \gamma^{+}$is required for production of IL-12. IL-12 subsequently triggers the activation of liver immune cells including NK and NKT cells. NOG mice lack mature T cells and functional NK cells. This role of IL-12 was also supported in NOG mice injected with CT26 colon tumor cells by the fact that miR-18a delivered by GNVs does not inhibit the growth of colon tumors that have metastasized to the liver. Nude mice which have both NK and NKT activity were found to inhibit the growth of metastasized tumors in the liver when injected with CT26 colon tumor cells. Although IL-12 has been shown to enhance the rejection of a variety of murine tumors, pre-clinical and clinical studies have revealed that IL-12 can produce severe toxicity [44]. Therefore, our finding that induction of IL-12 through KC IFN- $\gamma$ induced through the GNV/miR-18a axis in the liver will have less side-effects compared to systemic administration IL-12 has great potential for anti-cancer immune therapy.

This study addresses the question of not only mechanisms that regulate the induction of M1 macrophages but also the use of grapefruit-derived nanovectors (GNVs) as

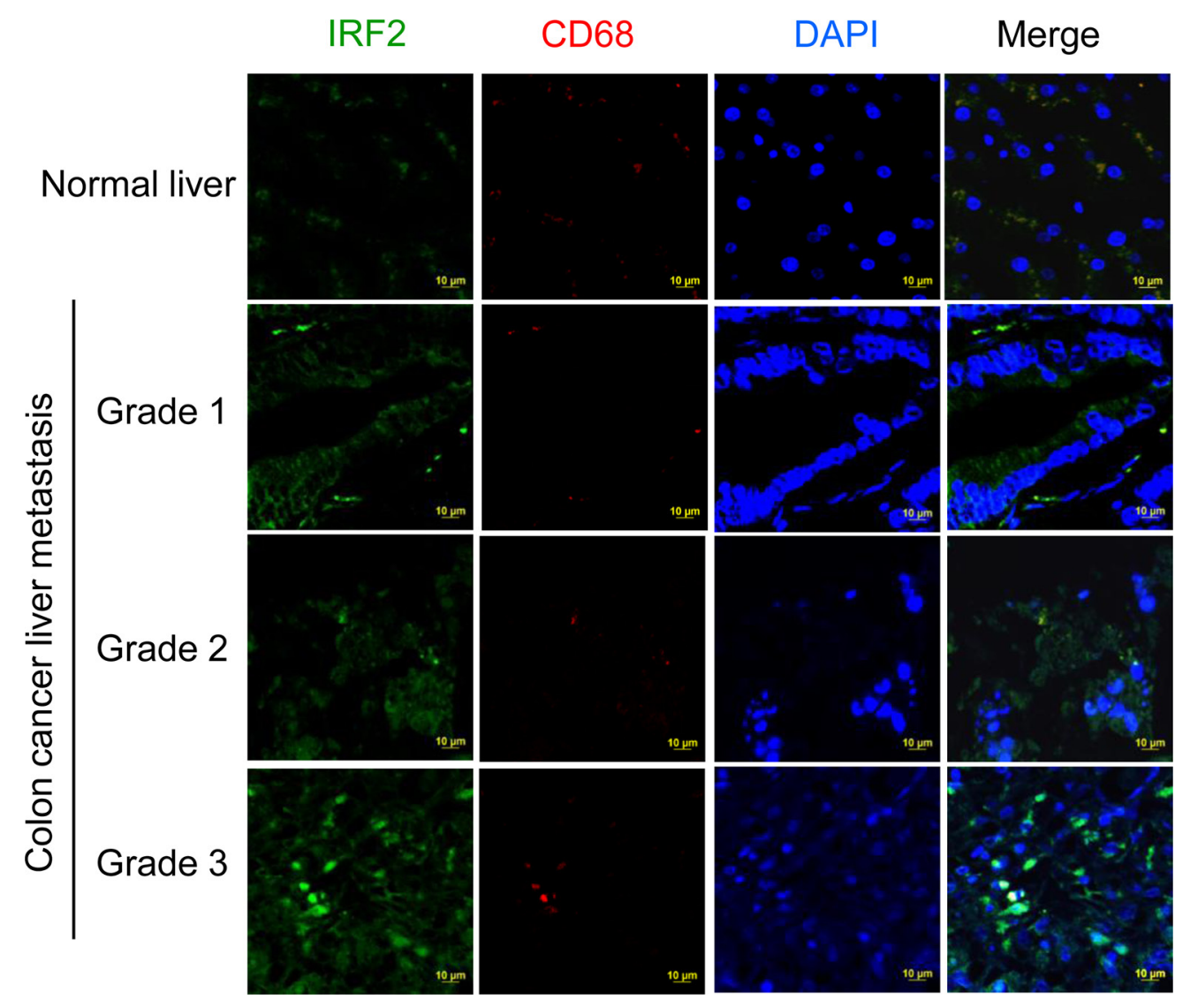

Figure 7: Up-regulation of IRF2 in metastatic liver tissue of colon cancer patients. Double staining of human colon cancer tissue sections with antibodies against IRF2 (green) and against CD68 (red) followed by detection of fluorescence. 
a therapeutic vehicle for treatment of liver metastasis of colon cancer. We identified miR-18a as a previously unrecognized inhibitor for liver metastasis through the induction of M1 macrophage. These results provide new insights into the molecular mechanisms of miR-18a-mediated macrophage polarization and shed light on new therapies for cancers through a miR-18a-mediated induction of M1 macrophages. The means and method we demonstrated in this study are a major step in the development of high capacity GNVs to deliver therapeutic RNA in general.

Our findings established a basis for further investigating whether IRF2 acts as a suppressor to directly inhibit expression of IFN $\gamma$. Alternatively, it is possible that as a result of miR-18a-mediated down regulation of levels of IRF2, the level of IRF1 is increased. An imbalance between IRF-1 and IRF-2 [43, 44], the activator and repressor of IFN responses, respectively, may contribute to the altered expression of IFN $\gamma$. Therefore, increasing IRF1/IRF-2 ratios by targeted delivery of miR-18a to IRF2 overexpressed macrophages is expected to induce IFN $\gamma$.

Systemic delivery of targeted vectors presents major challenges for developing an effective anti-cancer immunotherapy. One of advantages of an OGNV based delivering system is that OGNV is selectively taken up by liver KCs, not hepatocytes. Targeted delivery is particularly important for miRNA mediated therapy. One miRNA could regulate a number of genes, and among the potentially targeted genes, preferential miRNA targeted genes may be dependent on the levels of that miRNA and the accessibility and availability of the miRNA targeted genes. It is conceivable that the mRNA expression profile of one type of cell, such as KCs, targeted by OGNVs could be different from the hepatocytes. Therefore, genes targeted by miR-18a in KCs are unlikely the same ones if miR-18a is overexpressed in other types of cells such as hepatocytes. It has been reported that over expression of miR-18a in hepatocytes may contribute to the pathogenicity of liver cancer [45]. Our real-time PCR data showed that the level of miR-18a in hepatocytes was not increased following an intravenous administration of OGNVs/miR-18a. This could be due to OGNVs/miR-18a primarily being taken up by KCs. The exploitation of the liver macrophages to mediate the immune therapeutic effects of miRNA, such as miR-18a delivered by GNVs, can circumvent limitations of miRNA targeted delivery. Kupffer cells are the first point of contact to administer miRNAs encapsulated in OGNVs, affording an opportunity to directly modulate their functional activity. Therefore, besides of miRNAs, an OGNV based in vivo delivery system can also deliver other therapeutic agents which modulate liver macrophage activity and control macrophage lineage. OGNVs based targeting liver macrophage naturally take place without pressure on the host. Therefore, we do not expect that GNV based targeted delivery to KCs would be altered due host pressure built up as other delivery system.

\section{MATERIALS AND METHODS}

\section{FISH (fluorescence in situ hybridization)}

To visualize biotin conjugated miR-18a in the liver, tissue sections were deparaffinized and rehydrated. After permeabilization by adding $1 \%$ triton X-100, tissue sections were incubated in PBS containing $5 \mathrm{mg} / \mathrm{ml}$ of lysozyme at $37^{\circ} \mathrm{C}$ for $20 \mathrm{~min}$. Following a pre-incubation at $46^{\circ} \mathrm{C}$ for $1 \mathrm{~h}$ in hybridization buffer $(900 \mathrm{mM} \mathrm{NaCl}$; 20 mM Tris-HCl, pH 8.0; 1 mM EDTA, pH 8.0), tissues were hybridized with $0.1 \mu \mathrm{M}$ of Alexa Fluor ${ }^{\circledR}$ fluorescent conjugated streptavidin at $46^{\circ} \mathrm{C}$ overnight. After dehydrating the tissue sections in a graded ethanol series, i.e., $70 \%, 80 \%, 95 \%, 100 \%$ ethanol, nuclear chromatin was stained with 4', 6-diamidino-2-phenylindole (DAPI) and the tissues were analyzed using confocal laser scanning microscopy.

\section{Preparation and characterization of optimized GNVs (OGNVs)}

Grapefruit-derived lipids were prepared, as previously described [41]. In brief, the sucrose gradient purified grapefruit nanoparticles were harvested from the $30 \% / 45 \%$ interface (Supplementary Figure S1). The lipids were extracted with chloroform and dried under vacuum. The concentration of lipids was measured using the phosphate assay as described. To generate OGNVs, $200 \mathrm{nmol}$ of lipid was suspended in $200-400 \mu \mathrm{l}$ of $155 \mathrm{mM} \mathrm{NaCl}$ with $10 \mu \mathrm{g}$ of RNA. After UV irradiation at $500 \mathrm{~mJ} / \mathrm{cm}^{2}$ in a Spectrolinker (Spectronic Corp.) and bath sonication (FS60 bath sonicator, Fisher Scientific) for $30 \mathrm{~min}$, the pelleted particles were collected by centrifugation at $100,000 \mathrm{~g}$ for $1 \mathrm{~h}$ at $4{ }^{\circ} \mathrm{C}$. The size and zeta potential distribution of the particles was analyzed using a Zetasizer Nano ZS (Malvern Instrument, UK).

\section{Labeling RNA in OGNV with Exo-GLOW}

RNA in OGNVs was labeled with Exo-GLOWTM Exosome Labeling Kits (Cat \# EXOR100A-1, System Biosciences) in accordance with the manufacturer's instructions. $10 \mu \mathrm{l}$ of resuspended OGNVs with encapsulated RNA was diluted into $500 \mu \mathrm{l}$ of PBS with $50 \mu \mathrm{l}$ of $10 \mathrm{x}$ Exo-Red and incubated at $37^{\circ} \mathrm{C}$ for $10 \mathrm{~min}$. To stop the labeling reaction, $100 \mu$ of the ExoQuick-TC reagent was used and the reaction was placed on ice for $30 \mathrm{~min}$. After washing by centrifugation at 13,000 rpm for $3 \mathrm{~min}$, OGNVs were resuspended and were assessed for fluorescence intensity with an excitation maximum at $460 \mathrm{~nm}$ and emission maximum shift to $650 \mathrm{~nm}$. Details of other methods used in this study are described in the Supplementary Experimental Procedures. 


\section{Statistical analysis}

Statistical significance was determined by the Student's $t$ test. Differences between individual groups were analyzed by one- or two-way analysis of variance test. Differences were considered significantly when the $P$ value was less than 0.05 or 0.01 as indicated in the text.

\section{ACKNOWLEDGMENTS AND FUNDING}

This work was supported by grants from the National Institutes of Health (NIH) (R01AT008617, UH3TR000875) and the Louisville Veterans Administration Medical Center (VAMC) Merit Review Grants and VA Research Career Scientist Award (H.-G.Z.); and a grant from the Susan G. Komen Breast Cancer Foundation. We thank Dr. Jerald Ainsworth for editorial assistance.

\section{CONFLICTS OF INTEREST}

No potential conflicts of interest were disclosed

\section{REFERENCES}

1. Lujambio A, Akkari L, Simon J, Grace D, Tschaharganeh DF, Bolden JE, Zhao Z, Thapar V, Joyce JA, Krizhanovsky V, Lowe SW. Non-cell-autonomous tumor suppression by p53. Cell. 2013; 153:449-460.

2. Rushfeldt C, Sveinbjornsson B, Seljelid R, Smedsrod B. Early events of hepatic metastasis formation in mice: role of Kupffer and NK-cells in natural and interferon-gammastimulated defense. J Surg Res. 1999; 82:209-215.

3. Shiratori Y, Nakata R, Okano K, Komatsu Y, Shiina S, Kawase T, Sugimoto T, Omata M, Tanaka M. Inhibition of hepatic metastasis of colon carcinoma by asialo GM1positive cells in the liver. Hepatology. 1992; 16:469-478.

4. Roh MS, Kahky MP, Oyedeji C, Klostergaard J, Wang L, Curley SA, Lotzova E. Murine Kupffer cells and hepatic natural killer cells regulate tumor growth in a quantitative model of colorectal liver metastases. Clin Exp Metastasis. $1992 ; 10: 317-327$.

5. Matsumura H, Kondo T, Ogawa K, Tamura T, Fukunaga K, Murata S, Ohkohchi N. Kupffer cells decrease metastasis of colon cancer cells to the liver in the early stage. Int J Oncol. 2014; 45:2303-2310.

6. Miyagawa S, Miwa S, Soeda J, Kobayashi A, Kawasaki S. Morphometric analysis of liver macrophages in patients with colorectal liver metastasis. Clin Exp Metastasis. 2002; 19:119-125.

7. Van den Eynden GG, Majeed AW, Illemann M, Vermeulen PB, Bird NC, Hoyer-Hansen G, Eefsen RL, Reynolds AR, Brodt $\mathrm{P}$. The multifaceted role of the microenvironment in liver metastasis: biology and clinical implications. Cancer Res. 2013; 73:2031-2043.
8. Kruse J, von Bernstorff W, Evert K, Albers N, Hadlich S, Hagemann S, Gunther C, van Rooijen N, Heidecke CD, Partecke LI. Macrophages promote tumour growth and liver metastasis in an orthotopic syngeneic mouse model of colon cancer. Int J Colorectal Dis. 2013; 28:1337-1349.

9. Parker GA, Picut CA. Immune functioning in non lymphoid organs: the liver. Toxicol Pathol. 2012; 40:237-247.

10. Miyamoto M, Emoto M, Brinkmann V, van Rooijen N, Schmits R, Kita E, Kaufmann SH. Cutting edge: contribution of NK cells to the homing of thymic CD4+NKT cells to the liver. J Immunol. 2000; 165:1729-1732.

11. Seki S, Nakashima H, Nakashima M, Kinoshita M. Antitumor immunity produced by the liver Kupffer cells, NK cells, NKT cells, and CD8 CD122 T cells. Clin Dev Immunol. 2011; 2011:868345.

12. Seki S, Habu Y, Kawamura T, Takeda K, Dobashi H, Ohkawa T, Hiraide H. The liver as a crucial organ in the first line of host defense: the roles of Kupffer cells, natural killer (NK) cells and NK1.1 Ag+ T cells in T helper 1 immune responses. Immunol Rev. 2000; 174:35-46.

13. Jha AK, Huang SC, Sergushichev A, Lampropoulou V, Ivanova Y, Loginicheva E, Chmielewski K, Stewart KM, Ashall J, Everts B, Pearce EJ, Driggers EM, Artyomov MN. Network integration of parallel metabolic and transcriptional data reveals metabolic modules that regulate macrophage polarization. Immunity. 2015; 42:419-430.

14. Murray PJ, Allen JE, Biswas SK, Fisher EA, Gilroy DW, Goerdt S, Gordon S, Hamilton JA, Ivashkiv LB, Lawrence T, Locati M, Mantovani A, Martinez FO, et al. Macrophage activation and polarization: nomenclature and experimental guidelines. Immunity. 2014; 41:14-20.

15. Xue J, Schmidt SV, Sander J, Draffehn A, Krebs W, Quester I, De Nardo D, Gohel TD, Emde M, Schmidleithner L, Ganesan H, Nino-Castro A, Mallmann MR, et al. Transcriptomebased network analysis reveals a spectrum model of human macrophage activation. Immunity. 2014; 40:274-288.

16. Hao NB, Lu MH, Fan YH, Cao YL, Zhang ZR, Yang SM. Macrophages in tumor microenvironments and the progression of tumors. Clin Dev Immunol. 2012; 2012:948098.

17. Standiford TJ, Kuick R, Bhan U, Chen J, Newstead M, Keshamouni VG. TGF-beta-induced IRAK-M expression in tumor-associated macrophages regulates lung tumor growth. Oncogene. 2011; 30:2475-2484.

18. Umemura N, Saio M, Suwa T, Kitoh Y, Bai J, Nonaka K, Ouyang GF, Okada M, Balazs M, Adany R, Shibata T, Takami T. Tumor-infiltrating myeloid-derived suppressor cells are pleiotropic-inflamed monocytes/macrophages that bear M1- and M2-type characteristics. J Leukoc Biol. 2008; 83:1136-1144.

19. Bastos KR, Alvarez JM, Marinho CR, Rizzo LV, Lima MR. Macrophages from IL-12p40-deficient mice have a bias toward the M2 activation profile. J Leukoc Biol. 2002; $71: 271-278$. 
20. Ryan AE, Colleran A, O'Gorman A, O'Flynn L, Pindjacova J, Lohan P, O’Malley G, Nosov M, Mureau C, Egan LJ. Targeting colon cancer cell NF-kappaB promotes an anti-tumour M1-like macrophage phenotype and inhibits peritoneal metastasis. Oncogene. 2015; 34:1563-1574.

21. Santoni M, Massari F, Amantini C, Nabissi M, Maines F, Burattini L, Berardi R, Santoni G, Montironi R, Tortora G, Cascinu S. Emerging role of tumor-associated macrophages as therapeutic targets in patients with metastatic renal cell carcinoma. Cancer Immunol Immunother. 2013; 62: 1757-1768.

22. Costa NL, Valadares MC, Souza PP, Mendonca EF, Oliveira JC, Silva TA, Batista AC. Tumor-associated macrophages and the profile of inflammatory cytokines in oral squamous cell carcinoma. Oral Oncol. 2013; 49:216-223.

23. Heusinkveld M, de Vos van Steenwijk PJ, Goedemans R, Ramwadhdoebe TH, Gorter A, Welters MJ, van Hall T, van der Burg SH. M2 macrophages induced by prostaglandin E2 and IL-6 from cervical carcinoma are switched to activated M1 macrophages by CD4+ Th1 cells. J Immunol. 2011; 187:1157-1165.

24. Duluc D, Corvaisier M, Blanchard S, Catala L, Descamps P, Gamelin E, Ponsoda S, Delneste Y, Hebbar M, Jeannin P. Interferon-gamma reverses the immunosuppressive and protumoral properties and prevents the generation of human tumor-associated macrophages. Int J Cancer. 2009; 125:367-373.

25. Hata A, Lieberman J. Dysregulation of microRNA biogenesis and gene silencing in cancer. Sci Signal. 2015; 8:re3.

26. Yang F, Zhang W, Shen Y, Guan X. Identification of dysregulated microRNAs in triple-negative breast cancer (review). Int J Oncol. 2015; 46:927-932.

27. Joshi P, Middleton J, Jeon YJ, Garofalo M. MicroRNAs in lung cancer. World J Methodol. 2014; 4:59-72.

28. Oom AL, Humphries BA, Yang C. MicroRNAs: novel players in cancer diagnosis and therapies. Biomed Res Int. 2014; 2014:959461.

29. Cho WC. MicroRNAs as therapeutic targets and their potential applications in cancer therapy. Expert Opin Ther Targets. 2012; 16:747-759.

30. Parasramka MA, Ho E, Williams DE, Dashwood RH. MicroRNAs, diet, and cancer: new mechanistic insights on the epigenetic actions of phytochemicals. Mol Carcinog. 2012; 51:213-230.

31. Wang Z, Brandt S, Medeiros A, Wang S, Wu H, Dent A, Serezani CH. MicroRNA 21 is a homeostatic regulator of macrophage polarization and prevents prostaglandin E2mediated M2 generation. PLoS One. 2015; 10:e0115855.

32. Caescu CI, Guo X, Tesfa L, Bhagat TD, Verma A, Zheng D, Stanley ER. Colony stimulating factor-1 receptor signaling networks inhibit mouse macrophage inflammatory responses by induction of microRNA-21. Blood. 2015; 125:e1-13.
33. Xu S, Wei J, Wang F, Kong LY, Ling XY, Nduom E, Gabrusiewicz K, Doucette T, Yang Y, Yaghi NK, Fajt V, Levine JM, Qiao W, et al. Effect of miR-142-3p on the M2 macrophage and therapeutic efficacy against murine glioblastoma. J Natl Cancer Inst. 2014; 106.

34. Veremeyko $\mathrm{T}$, Siddiqui $\mathrm{S}$, Sotnikov I, Yung A, Ponomarev ED. IL-4/IL-13-dependent and independent expression of miR-124 and its contribution to M2 phenotype of monocytic cells in normal conditions and during allergic inflammation. PLoS One. 2013; 8:e81774.

35. Zhou D, Huang C, Lin Z, Zhan S, Kong L, Fang C, Li J. Macrophage polarization and function with emphasis on the evolving roles of coordinated regulation of cellular signaling pathways. Cell Signal. 2014; 26: 192-197.

36. Moore CS, Rao VT, Durafourt BA, Bedell BJ, Ludwin SK, Bar-Or A, Antel JP. miR-155 as a multiple sclerosis-relevant regulator of myeloid cell polarization. Ann Neurol. 2013; 74:709-720.

37. Jenne CN, Kubes P. Immune surveillance by the liver. Nat Immunol. 2013; 14:996-1006.

38. Pellicoro A, Ramachandran P, Iredale JP, Fallowfield JA. Liver fibrosis and repair: immune regulation of wound healing in a solid organ. Nat Rev Immunol. 2014; 14:181-194.

39. Bilzer M, Roggel F, Gerbes AL. Role of Kupffer cells in host defense and liver disease. Liver Int. 2006; 26: $1175-1186$.

40. Wang Q, Ren Y, Mu J, Egilmez NK, Zhuang X, Deng Z, Zhang L, Yan J, Miller D, Zhang HG. Grapefruit-derived nanovectors use an activated leukocyte trafficking pathway to deliver therapeutic agents to inflammatory tumor sites. Cancer Res. 2015; 75:2520-9. doi: 10.1158/0008-5472.CAN-14-3095.

41. Wang Q, Zhuang X, Mu J, Deng ZB, Jiang H, Zhang L, Xiang X, Wang B, Yan J, Miller D, Zhang HG. Delivery of therapeutic agents by nanoparticles made of grapefruitderived lipids. Nat Commun. 2013; 4:1867.

42. Humphreys KJ, McKinnon RA, Michael MZ. miR-18a inhibits CDC42 and plays a tumour suppressor role in colorectal cancer cells. PLoS One. 2014; 9:e112288.

43. Jiang H, Wang P, Wang Q, Wang B, Mu J, Zhuang X, Zhang L, Yan J, Miller D, Zhang HG. Quantitatively controlling expression of miR-17 92 determines colon tumor progression in a mouse tumor model. Am J Pathol. 2014; 184:1355-1368.

44. Leonard JP, Sherman ML, Fisher GL, Buchanan LJ, Larsen G, Atkins MB, Sosman JA, Dutcher JP, Vogelzang NJ, Ryan JL. Effects of single-dose interleukin-12 exposure on interleukin-12-associated toxicity and interferon-gamma production. Blood. 1997; 90:2541-2548.

45. Liu WH, Yeh SH, Lu CC, Yu SL, Chen HY, Lin CY, Chen DS, Chen PJ. MicroRNA-18a prevents estrogen receptoralpha expression, promoting proliferation of hepatocellular carcinoma cells. Gastroenterology. 2009; 136:683-693. 